\title{
Soil-transmitted helminthiasis in Latin America and the Caribbean: modelling the determinants, prevalence, population at risk and costs of control at sub-national level
}

\author{
Josh Colston ${ }^{1}$, Martha Saboyá2 \\ ${ }^{1}$ Inter-American Development Bank, Washington DC 20577, USA; ${ }^{2}$ Pan American Health Organization, \\ Washington DC 20037, USA
}

\begin{abstract}
We present an example of a tool for quantifying the burden, the population in need of intervention and resources need to contribute for the control of soil-transmitted helminth (STH) infection at multiple administrative levels for the region of Latin America and the Caribbean (LAC). The tool relies on published STH prevalence data along with data on the distribution of several STH transmission determinants for 12,273 sub-national administrative units in 22 LAC countries taken from national censuses. Data on these determinants was aggregated into a single risk index based on a conceptual framework and the statistical significance of the association between this index and the STH prevalence indicators was tested using simple linear regression. The coefficient and constant from the output of this regression was then put into a regression formula that was applied to the risk index values for all of the administrative units in order to model the estimated prevalence of each STH species. We then combine these estimates with population data, treatment thresholds and unit cost data to calculate total control costs. The model predicts an annual cost for the procurement of preventive chemotherapy of around US\$ 1.7 million and a total cost of US\$ 47 million for implementing a comprehensive STH control programme targeting an estimated 78.7 million school-aged children according to the WHO guidelines throughout the entirety of the countries included in the study. Considerable savings to this cost could potentially be made by embedding STH control interventions within existing health programmes and systems. A study of this scope is prone to many limitations which restrict the interpretation of the results and the uses to which its findings may be put. We discuss several of these limitations.
\end{abstract}

Keywords: soil-transmitted helminthiasis, Latin America and the Caribbean, social determinants, model.

\section{Introduction}

Soil-transmitted helminthiasis ( $\mathrm{STH})$, is the most prevalent of the so-called "Neglected Infectious Diseases" (NIDs), a group of conditions which disproportionately affect poor and marginalized groups, leading to a high burden of morbidity and exacerbating inequalities. The infectious agents are certain species of parasitic worms-helminths, notably Ascaris lumbricoides, Trichuris trichiura and the hookworms (Ancylostoma duodenale and Necator americanus) that inhabit the gastrointestinal tract where they survive for up to four years producing many thousands of eggs per day that are passed by the host in the faeces and may survive in the external environment, remaining viable for several years (Hotez et al. 2006)." Infection occurs when fertile eggs are ingested from contaminated water or vegetables grown in contami-

Corresponding author:

Josh Colston

1818 Lamont St NW, Washington DC 20010, USA

Tel. +1 2026797723

E-mail: joshcolston@gmail.com nated soil or, for hookworm infections, when larval forms penetrate the naked feet from the ground below. Rural conditions of poor sanitation where there is a lack of safe water and inadequate disposal of human excreta therefore sustain transmission of the STH. Other determinants include age (intensity of infection usually peaks in childhood), lack of education, poor living conditions, living in a wet, tropical climate and being involved in agricultural activities (Smith et al., 2001). These infections rarely cause death but their public health consequences are manifest in the chronic, insidious effects that the condition has such as malnutrition, anaemia, impeded growth and increased susceptibility to other infections (Montresor et al., 1998). The STH account for $13.8 \%$ of the combined burden of the NTDs in terms of disability-adjusted life years (DALYs), as described by Murray and Lopez (1997) and 7\% in terms of mortality in Latin America and the Caribbean (LAC), the second highest of those diseases after Chagas' disease (Bitrán et al., 2009).

In both pre-school (1-4 years) and school-aged (5-14 years) children, the age-groups most at risk, STH infection stunts physical growth and impairs the development of cognitive function, hampering performance 
and attendance within the education system and ultimately hindering economic development (Montresor et al., 1998; Smith et al., 2001; Hotez et al., 2006). Social absenteeism, decreased worker-productivity, low self esteem and social exclusion are among the longer-term consequences (WHO, 2006). The recommended control strategy is a population-based approach whereby all members of a target population receive treatment with anthelminthic drugs, usually albendazole or mebendazole, regardless of infection status. This kind of preventive chemotherapy (PCT), known as mass drug administration (MDA), can be rolled out cheaply and it is justified as there are no negative consequences for uninfected individuals receiving the drug (WHO, 2006)1. However, an integrated approach tackling determinants like water and sanitation access is necessary for achieving and sustaining control goals.

There are not enough data available on STH prevalence at sub-national level in LAC. There is a need for statistical and geospatial tools that can accurately characterise the size and spatial distribution of the population-at-risk of STH infection, including stratification of areas by infection risk, in order to implement cost-effective control measures on a large scale (Brooker and Michael, 2000; Brooker et al., 2006). Increasingly, geographical information systems (GIS) are being employed to understand, model and predict the distribution and trends of infectious diseases in general and helminthiases in particular, to serve as inputs for programmatic decision-making (Brooker et al., 2003, 2006; Brooker, 2007; Sturrock et al., 2009; Zhou et al., 2009). Furthermore, several attempts have been made to quantify the burden ${ }^{2}$, the population in need of $\mathrm{MDA}^{3}$ and the resource needs for the control ${ }^{4}$ of STH at the global, regional, national and sub-national levels. To our knowledge, no tool exists that can estimate issues things at multiple levels. We present an example of such a tool for LAC that uses published STH prevalence data along with data on the distribution of several transmission determinants. In an attempt to provide inputs for programmatic decision-making, the specific aims of the study were to:

(i) compile a database of indicators of socio-economic determinants of STH transmission for the second-level administrative units (municipalities) in the countries of the LAC region;

(ii) construct an aggregate index of STH risk based on the statistical association of these indicators with published STH prevalence estimates and their relative proximity as determinants;

(iii) apply a regression model to the index to predict the prevalence of STH for every second-level administrative unit in every country in LAC for which data are available; and

(iv) estimate the number of cases of STH in children and the number of rounds of MDA, the number of doses of albendazole 5 and the financial resources for purchasing and delivering drugs that would be required to treat all the children according to the $\mathrm{WHO}$ guidelines.

\section{Materials and methods}

\section{Indicators of determinants of STH transmission}

We compiled a list of what might be called "socioeconomic determinants" of STH transmission, that is to say, factors related to individual living conditions and socio-economic circumstances that are independent of environmental or ecological factors but known to be determinants of specific individual's risk of being infected with STH. The following factors were selected:

(i) living in a house that has dirt or earth floors (Gamboa et al., 1998; Morales-Espinoza et al., 2003; Cattaneo et al., 2007);

(ii) lack of education ${ }^{6}$;

(iii) crowded living conditions ${ }^{7}$;

(iv) lack of access to safe drinking water ${ }^{8}$;

(v) lack of access to sanitation facilities ${ }^{9}$; and

(vi) poverty ${ }^{10}$.

Next, a review of data sources was conducted to identify indicators for each of these determinants that are available for second-level administrative units of countries in the LAC region. Most of the countries of this region make available online detailed census data relating to various aspects of their populations and households that can be disaggregated to sub-national levels. Therefore these data were consulted for information relating to STH determinants. Several important countries did not have census data publicly available at sub-national levels (notably Haiti, Jamaica and Cuba). These countries were therefore excluded from the study as were the smaller countries of the Caribbean as they are not classified as STH endemic countries. For the remaining, the following information was gathered:

\section{Living in a house that has dirt or earth floors}

Almost all of the countries for which data was available included in their census some kind of question about the principal material used in the construction of the floors of the respondent's dwelling and had "earth" 
or "dirt" ("tierra" in Spanish) as one of the possible responses. The notable exceptions to this were Brazil, Guyana, Suriname and Uruguay whose published census data did not contain information on floor material.

\section{Lack of education}

Several indicators were considered for inclusion (including the adult literacy rate) but many were found not to be available for every country. The variable that was available for the most countries was the proportion of the population aged $\geq 15$ years with no secondary education (no schooling above primary level), so this was selected as a proxy for lack of education.

\section{Overcrowded living conditions}

The measure that was chosen as an indicator here was the average number of residents per household, an indicator often referred to in the literature as the "average household size". This is a fairly crude measure and one can think of many biases and other problems that might affect it. More sophisticated indicators are available (e.g. the proportion of households with $\geq x$ number of residents per bedroom) but the data necessary to calculate these were not available for many of the countries in the study, whereas the average residents per household requires only very basic data that is available for all the countries at sub-national level.

\section{Lack of access to safe drinking water}

The categories of water sources differ considerably from country to country so a methodology was need-

${ }^{1}$ In fact, minor adverse events that have been reported but they are temporary and mainly occur in infected individuals in the first round of treatment as a result of the body's response to the dying of the worm.

${ }^{2}$ de Silva and others apply a methodology (originally employed by Chan and colleagues) that relies on the observed relationships between prevalence and intensity of infection to national level prevalence estimates, which represent the averages of prevalences obtained from individual studies in each country based on a literature search (Chan et al., 1994; de Silva et al., 2003). The Pan American Health Organization (PAHO) present information from the same database of STH prevalence estimates as used in this study, but analyse it only at the country level (PAHO, 2009). ${ }^{3}$ The World Health Organization (WHO) applies a new algorithm to national level epidemiological, demographic, sanitation and ecological data in order to estimate the number of children requiring PCT for STH and then sum these and present them at national and global level (WHO, 2011).

${ }^{4}$ Bitran and others calculate the costs associated with the control and elimination of the neglected tropical diseases (NTDs) in ed to standardise the classification of sources into "safe" and "unsafe". The website of the WHO/UNICEF Joint Monitoring Programme (JMP) for Water Supply and Sanitation $(2003,2010)$ gives definitions of "improved" and "unimproved" sources of drinking water as well as reports for each country summarising the sources of data on water coverage (including censuses) and specifying how the nationallevel coverage rates were calculated based on the variable categories used. By applying the same methodology to the individual administrative units that the JMP applies at the national level, it was possible to calculate the proportion of households lacking access to improved drinking water sources at the sub-national levels. In some cases, it was necessary to adjust the figures in order to take into account, for example, the proportion of traditional wells that are "improved". In other cases, it was necessary to disaggregate the data according to whether the administrative unit is urban or rural as the proportions differ according to area of residence.

\section{Lack of access to sanitation facilities}

Almost all of the national censuses analysed had collected data on the household facilities for collecting and disposing of human excreta and waste waters. The JMP sanitation country reports specify, for each country and data source, how the variable categories translate into "improved" and "unimproved" sanitation facilities. This methodology was employed by this study to calculate the proportion of households lacking access to improved sanitation facilities at the second level of administrative division.

LAC, including STH (Bitrán et al., 2009).

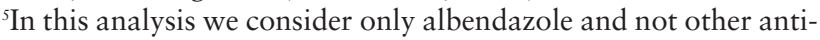
helminthic drugs because this is the drug that most countries in LAC report using in their STH programs and the one for which the best unit cost data is available.

${ }^{6}$ Children with less educated mothers (Quihui et al., 2006), parents or guardians (Maia et al., 2009; Hui, 2011) found that STH infection rate decreased alongside increases in health knowledge following education interventions.

${ }^{7}$ Household size (Asaolu et al., 1992), family size (Al-Mekhlafi et al., 2007), overcrowding (Brooker et al., 2006).

${ }^{8}$ Lack of access to safe drinking water (Gamboa et al., 1998; Morales-Espinoza et al., 2003; Brooker et al., 2006; Hotez et al., 2006); using untreated water supply (Ahmed et al., 2011).

${ }^{9} \mathrm{~A}$ systematic review and meta-analysis revealed that sanitation is associated with a reduced risk of transmission of STH (Ziegelbauer et al., 2012).

${ }^{10}$ Low household income (Quihui et al., 2006; Al-Mekhlafi et al., 2007), socio-economic status (Brooker et al., 2006), wealth (Balen et al., 2011). 
Table 1. Meta-data on sources, level of administrative division and availability of five socio-economic determinant indicators by country.

\begin{tabular}{|c|c|c|c|c|c|c|c|c|c|}
\hline Country & Data source & Year & 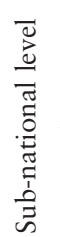 & Administrative unit & 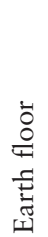 & 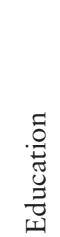 & $\begin{array}{l}0 \\
. \\
0 \\
\vdots \\
0 \\
0 \\
0 \\
0 \\
0 \\
0\end{array}$ & 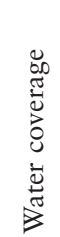 & 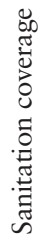 \\
\hline Argentina & $\begin{array}{l}\text { National census of populations and } \\
\text { households }\end{array}$ & 2001 & $2^{\text {nd }}$ & Department & $\checkmark$ & $\checkmark$ & $\checkmark$ & $\checkmark$ & $\checkmark$ \\
\hline Belize & Housing and population census & 2000 & $1^{\text {st }}$ & District & $\checkmark$ & $\checkmark$ & $\checkmark$ & $\checkmark$ & $\checkmark$ \\
\hline Bolivia & Census of population and households & 2001 & $2^{\text {nd }}$ & Province & $\checkmark$ & $(\sqrt{ })^{a}$ & $\checkmark$ & $\checkmark$ & $\checkmark$ \\
\hline Brazil & Demographic census & 2000 & $2^{\text {nd }}$ & Municipality & $\checkmark$ & $(\sqrt{ })^{\mathrm{b}}$ & $\checkmark$ & $\checkmark$ & $\checkmark$ \\
\hline Chile & Census of population and households & 2002 & $2^{\text {nd }}$ & Province & $\checkmark$ & $\checkmark$ & $\checkmark$ & $\checkmark$ & $\checkmark$ \\
\hline Colombia & General census & 2005 & $2^{\text {nd }}$ & Municipality & $\checkmark$ & $\checkmark$ & $\checkmark$ & $\checkmark$ & $\checkmark$ \\
\hline Costa Rica & $\begin{array}{l}\text { National census of population and } \\
\text { households }\end{array}$ & 2001 & $2^{\text {nd }}$ & Canton & $\checkmark$ & $\checkmark$ & $\checkmark$ & $\checkmark$ & $\checkmark$ \\
\hline Cuba & - & - & - & - & - & - & - & - & - \\
\hline Dominican Republic & $\begin{array}{l}7^{\text {th }} \text { National census of population } \\
\text { and households }\end{array}$ & 2002 & $2^{\text {nd }}$ & Municipality or municipal district & $\checkmark$ & $\checkmark$ & $\checkmark$ & $\checkmark$ & $\checkmark$ \\
\hline Ecuador & $\begin{array}{l}6^{\text {th }} \text { Population census and } 5^{\text {th }} \text { of } \\
\text { households }\end{array}$ & 2001 & $2^{\text {nd }}$ & Canton & $\checkmark$ & $\checkmark$ & $\checkmark$ & $\checkmark$ & $\checkmark$ \\
\hline El Salvador & $\begin{array}{l}6^{\text {th }} \text { Population census and } 5^{\text {th }} \text { of } \\
\text { households }\end{array}$ & 2007 & $2^{\text {nd }}$ & Municipality & $\checkmark$ & $\checkmark$ & $\checkmark$ & $\checkmark$ & $\checkmark$ \\
\hline Guatemala & $\begin{array}{l}11^{\text {th }} \text { National population census and } \\
6^{\text {th }} \text { of households }\end{array}$ & 2002 & $2^{\text {nd }}$ & Municipality & $\checkmark$ & $\checkmark$ & $\checkmark$ & $\checkmark$ & $\checkmark$ \\
\hline Guyana & Population and housing census & 2002 & $1^{\mathrm{st}}$ & Region & - & $\checkmark$ & $\checkmark$ & $\checkmark$ & $\checkmark$ \\
\hline Haiti & - & - & - & - & - & - & - & - & - \\
\hline Honduras & $\begin{array}{l}16^{\text {th }} \text { Population census and } 5^{\text {th }} \text { of } \\
\text { households }\end{array}$ & 2001 & $2^{\text {nd }}$ & Municipality & $\checkmark$ & $\checkmark$ & $\checkmark$ & $\checkmark$ & $\checkmark$ \\
\hline Jamaica & - & - & - & - & - & - & - & - & - \\
\hline Mexico & Census of population and households & 2000 & $2^{\text {nd }}$ & Municipality & $\checkmark$ & $\checkmark$ & $\checkmark$ & $\checkmark$ & $\checkmark$ \\
\hline Nicaragua & $\begin{array}{l}8^{\text {th }} \text { Census of population and } 4^{\text {th }} \text { of } \\
\text { households }\end{array}$ & 2005 & $2^{\text {nd }}$ & Municipality & $\checkmark$ & $\checkmark$ & $\checkmark$ & $\checkmark$ & $\checkmark$ \\
\hline Panama & Census of population and households & 2000 & $2^{\text {nd }}$ & District & $\checkmark$ & $\checkmark$ & $\checkmark$ & $\checkmark$ & $\checkmark$ \\
\hline Paraguay & $\begin{array}{l}\text { National census of population and } \\
\text { households }\end{array}$ & 2002 & $2^{\text {nd }}$ & District & $\checkmark$ & $\checkmark$ & $\checkmark$ & $\checkmark$ & $\checkmark$ \\
\hline Peru & Census of population and households & 2007 & $2^{\text {nd }}$ & Province & $\checkmark$ & $\checkmark$ & $\checkmark$ & $\checkmark$ & $\checkmark$ \\
\hline Suriname & The $7^{\text {th }}$ Population and housing census & 2004 & $2^{\text {nd }}$ & Resort & - & $\checkmark$ & $\checkmark$ & $(\checkmark)^{c}$ & $\checkmark$ \\
\hline Trinidad \& Tobago & Housing and population census & 2000 & $2^{\text {nd }}$ & $\begin{array}{l}\text { Regional corporations } \\
\text { or municipalities }\end{array}$ & - & $\checkmark$ & $\checkmark$ & $\checkmark$ & $\checkmark$ \\
\hline Uruguay & Census phase 1 & 2004 & $1^{\text {st }}$ & - & - & - & $\checkmark$ & - & - \\
\hline Venezuela & Census of population and households & 2001 & $2^{\text {nd }}$ & Municipality or municipal district & $\checkmark$ & $\checkmark$ & $\checkmark$ & $\checkmark$ & \\
\hline
\end{tabular}

${ }^{a}$ Data for Bolivia was only available from 10-year-age groups so the education variable applies to the population aged $\geq 20$ years, rather than from 15 years upwards;

'Proportion of the population aged $\geq 15$ that have 7 years of education or fewer;

"Proportion of households "with tap-number 1, 2" ("Woonverblijven met leidingwater 1,2 -aantal"). 


\section{Poverty}

Several countries make data available on indicators of poverty at sub-national level either as a predefined indicator as part of their reporting of census data (if they are derived from this source) or on the website of their respective statistical authorities. In some cases, the human development index (HDI) was available at this level, while in others, indicators based on some definition of unsatisfied basic needs had been calculated. However, this was by no means the case for all the countries and in those cases where an indicator of poverty was available, it usually incorporated some aspect of the other indicators of determinants already considered in this study with respect to its calculation. We therefore decided that indicators of poverty would not be included in the analysis.

Table 1 presents the source and year of the data for each major country in LAC, whether each of the five risk-factor indicators was available at the sub-national level and, if so, at what level. The results of this review was a database of 12,273 sub-national administrative units (most at the second level, but some at the first for brevity these units are referred to as "municipalities" even if by no means every country uses the Spanish term "municipio") in 22 LAC countries which provided the following information for each unit:

(i) earth floors: the proportion of households with floors made only of earth or dirt;

(ii) education: the proportion of the population $\geq 15$ years with no secondary education;

(iii) overcrowding: the average number of residents per household;

(iv) lack of water: the proportion of households that lack improved drinking-water sources; and

(v) lack of sanitation: the proportion of households that lack improved sanitation facilities.

Table 2 summarises key features of these five indicators. Importantly, four of the indicators are proportions, while just one (overcrowding) is a continuous variable. This was to have important consequences when it came to assigning weights to the variables.

\section{STH prevalence data}

The Pan American Health Organization (PAHO) has compiled a database based on a systematic review of estimates of prevalence and intensity of STH infections at the second-administrative level in LAC published between 2000 and 2010. Details of the criteria for inclusion in this database have been described elsewhere (Saboyá et al., 2011). For the purposes of this study, we further excluded all data points that did not meet the following criteria:

(i) estimated prevalence in school-aged children (age 514 years) or preschool-aged children (age 1-4 years);

(ii) estimated cumulative STH prevalence (i.e. prevalence of any worm infection);

(iii) estimated prevalence of any category of infection (i.e. estimates of prevalence of only high-intensity infections were excluded); and

(iv) pertained to countries for which there were data on the selected determinants (data points from Haiti and Cuba were excluded based on this criterion; Jamaica did not meet this criterion either but was already excluded based on the previous criteria).

Where there was more than one prevalence estimate in the same administrative unit in different years, we included only the most recent estimate. Where there was more than one estimate in the same unit in the same year, we took the mean of the values. In the case of Belize, the prevalence data were estimated at the first administrative level (the district) but the determinants applied to the second level (the village or town). We therefore summed the indicators up to the level of the district, which was justified by the fact that the Belize districts are of similar geographical and population size to many second-level administrative units in other countries. The resulting indicators are described in Table 2.

\section{Conceptual framework}

Fig. 1 shows a simplified, conceptual, hierarchical framework for determinants of STH transmission. It is important to take into account the relative proximity

Table 2. Summary of indicators of selected determinants.

\begin{tabular}{|c|c|c|c|c|c|c|}
\hline Indicator & Type of variable & Observations & Mean & $\begin{array}{c}\text { Standard } \\
\text { deviation }(\mathrm{SD})\end{array}$ & Minimum & Maximum \\
\hline Earth floors & Proportion & 6,654 & $21.5 \%$ & 0.21 & $0.0 \%$ & $98.0 \%$ \\
\hline Education & Proportion & 12,250 & $70.0 \%$ & 0.16 & $0.0 \%$ & $100.0 \%$ \\
\hline Overcrowding & Continuous & 12,271 & 4.1 & 0.63 & 2.5 & 9.4 \\
\hline Lack of water & Proportion & 12,252 & $16.4 \%$ & 0.16 & $0.0 \%$ & $100.0 \%$ \\
\hline Lack of sanitation & Proportion & 12,190 & $33.5 \%$ & 0.25 & $0.0 \%$ & $100.0 \%$ \\
\hline
\end{tabular}




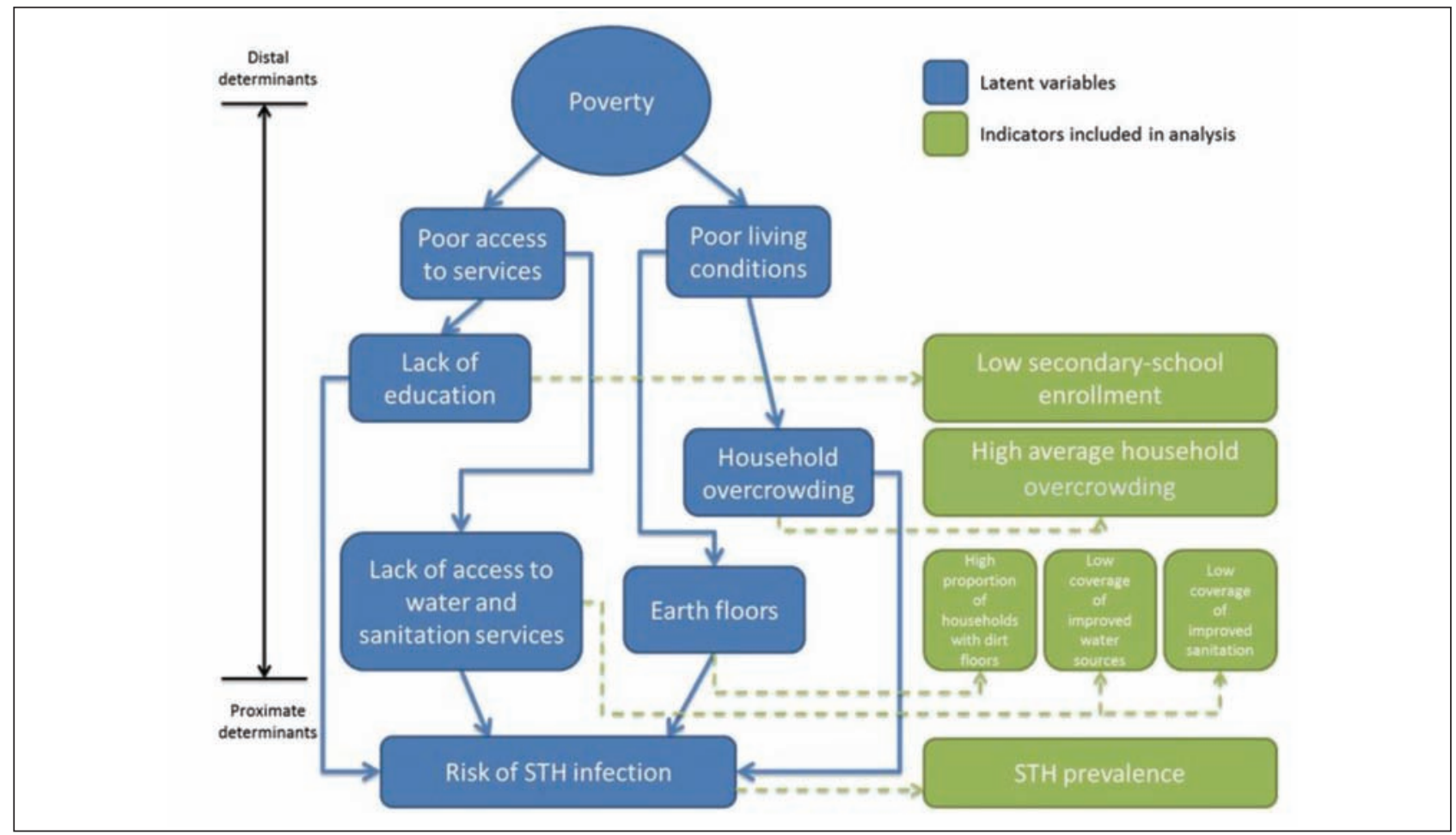

Fig. 1. Simplified conceptual hierarchical framework for determinants of STH infection.

of these determinants to the outcome in the analysis of the association of multiple variables on a health outcome. According to the framework proposed, lack of water and sanitation and earth floors impact very directly on the STH risk so they are classified as proximate determinants, while overcrowding is a more distal determinant and lack of education more distal still. This is because these factors act through a number of interrelated causal pathways, a chain of more proximate determinants that it is not possible to measure in this analysis (Victora et al., 1997). Proximity in this framework will be taken into account when aggregating the indicators into a single STH risk index. The more distal the determinant, the less weight its corresponding indicator will be assigned in contributing to the index.

\section{Geographical distribution of determinants of STH transmission}

In Figs. 2-5, the distribution of each of the five variables at the sub-national level (second-level of administrative division) have been mapped onto four subregions of LAC. The colour-scales have been divided into $20 \%$ increments with the exception of the education variable - which had a higher distribution and was therefore divided at the $60 \%$ level and then at $10 \%$ increments - and the overcrowding variable, which is not a proportion but a continuous variable and was therefore divided at 3.5 and then at increments of 0.5 .

\section{The Southern Cone countries}

What is immediately obvious from the maps of the Southern cone countries of Uruguay (for which only data on overcrowding were available), Argentina, Chile and Paraguay, is that for nearly all the indicators, it's possible to discern a gradient. This runs from the South and middle of Argentina, where the selected determinants have a low prevalence, up to the Gran Chaco region of northern Argentina and Paraguay, confirming that in these remote regions, housing conditions and access to services are poorer. However, this pattern is much less evident in the map of the education variable which shows a focus of low secondary education coverage in the centre of Argentina. Affluent Chile appears to have high access to water and sanitation and low levels of earth floors throughout its territory.

\section{The Andean Countries}

The distribution of selected determinants in Bolivia, Colombia, Ecuador and Peru show a mixed pattern. Earth floors and lack of education appears to trace a long strip of high rates along the length of the Andes 

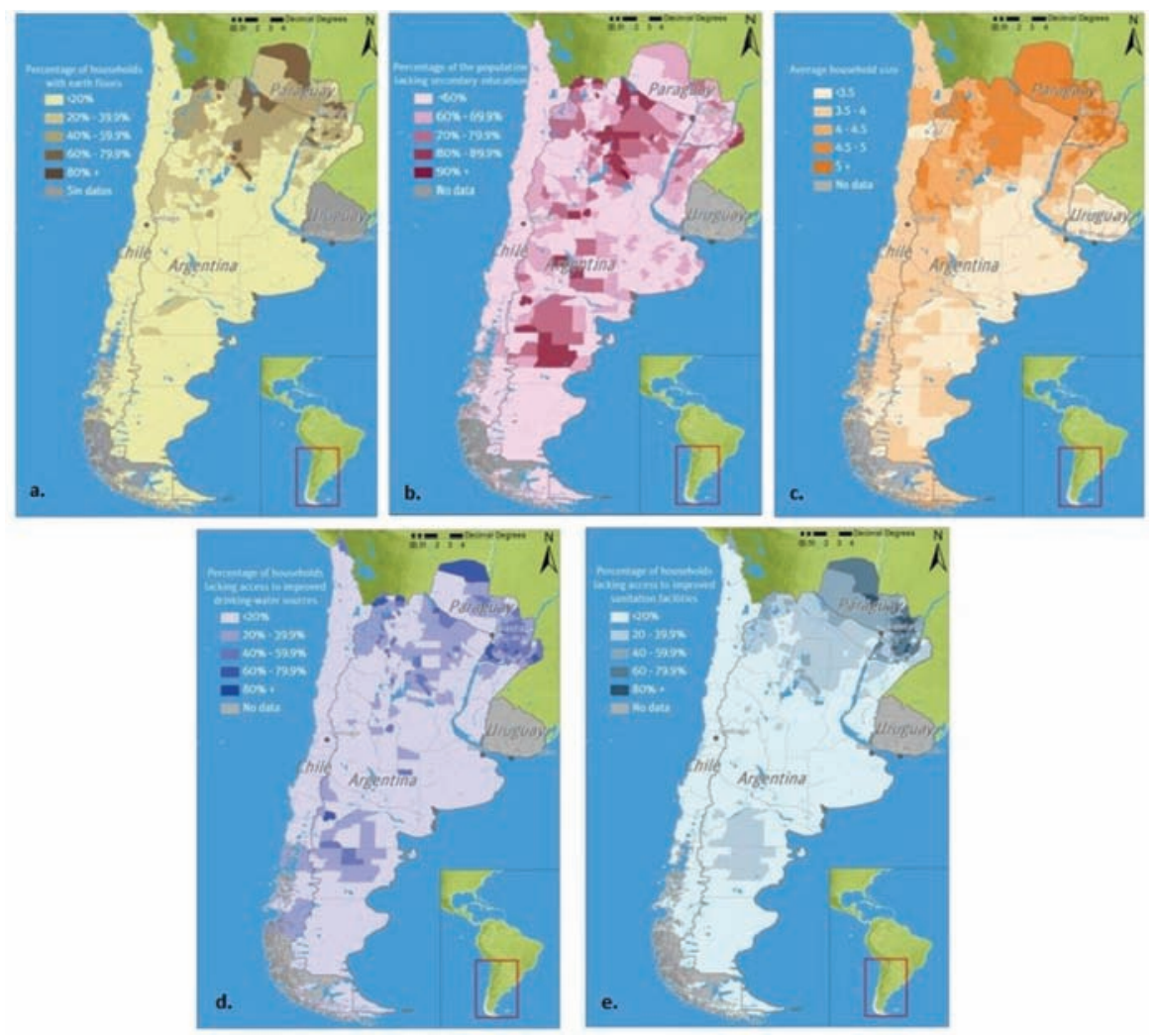

Fig. 2a-e. Distribution of indicators of earth floors (a); lack of education (b); overcrowding (average residents per household) (c); water supply (d); and sanitation (e) at sub-national level in the countries of the Southern Cone.

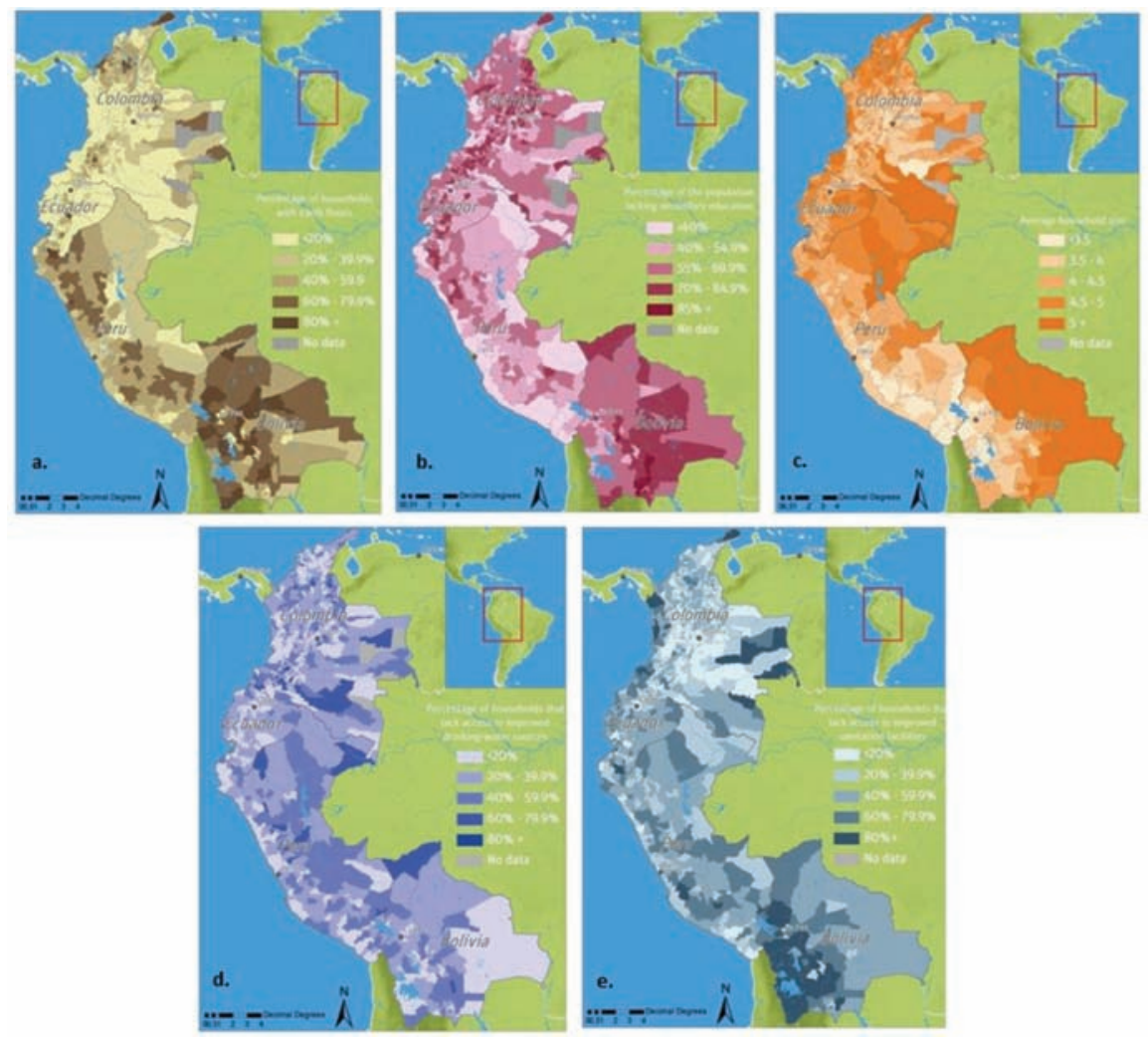

Fig. 3a-e. Distribution of indicators of earth floors (a); lack of education (b); overcrowding (average residents per household) (c); water supply (d); and sanitation (e) at sub-national level in the Andean countries. 

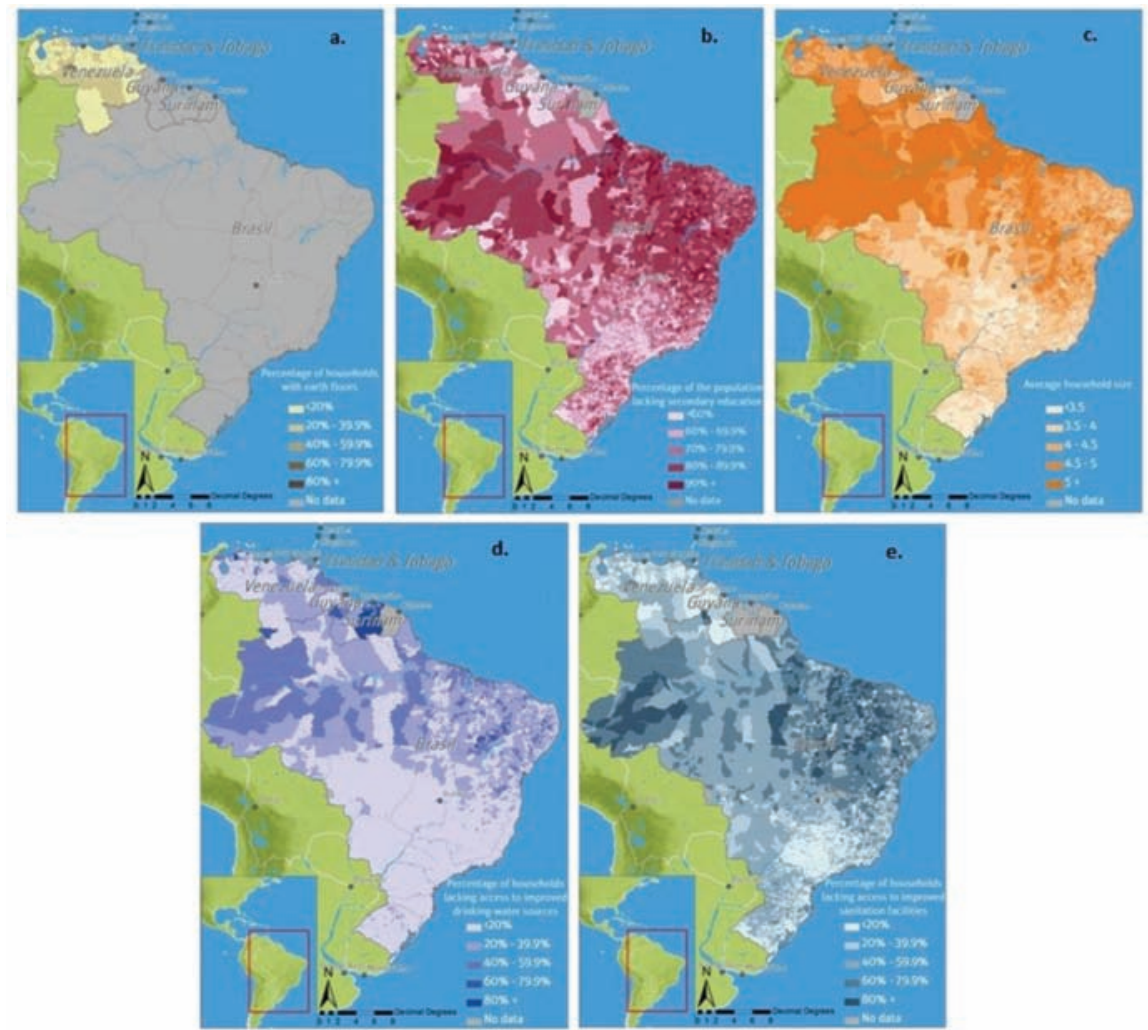

Fig. 4a-e. Distribution of indicators of earth floors (a); lack of education (b); overcrowding (average residents per household) (c); water supply (d); and sanitation (e) at sub-national level in Brazil, Venezuela and the non-Latin Caribbean countries.
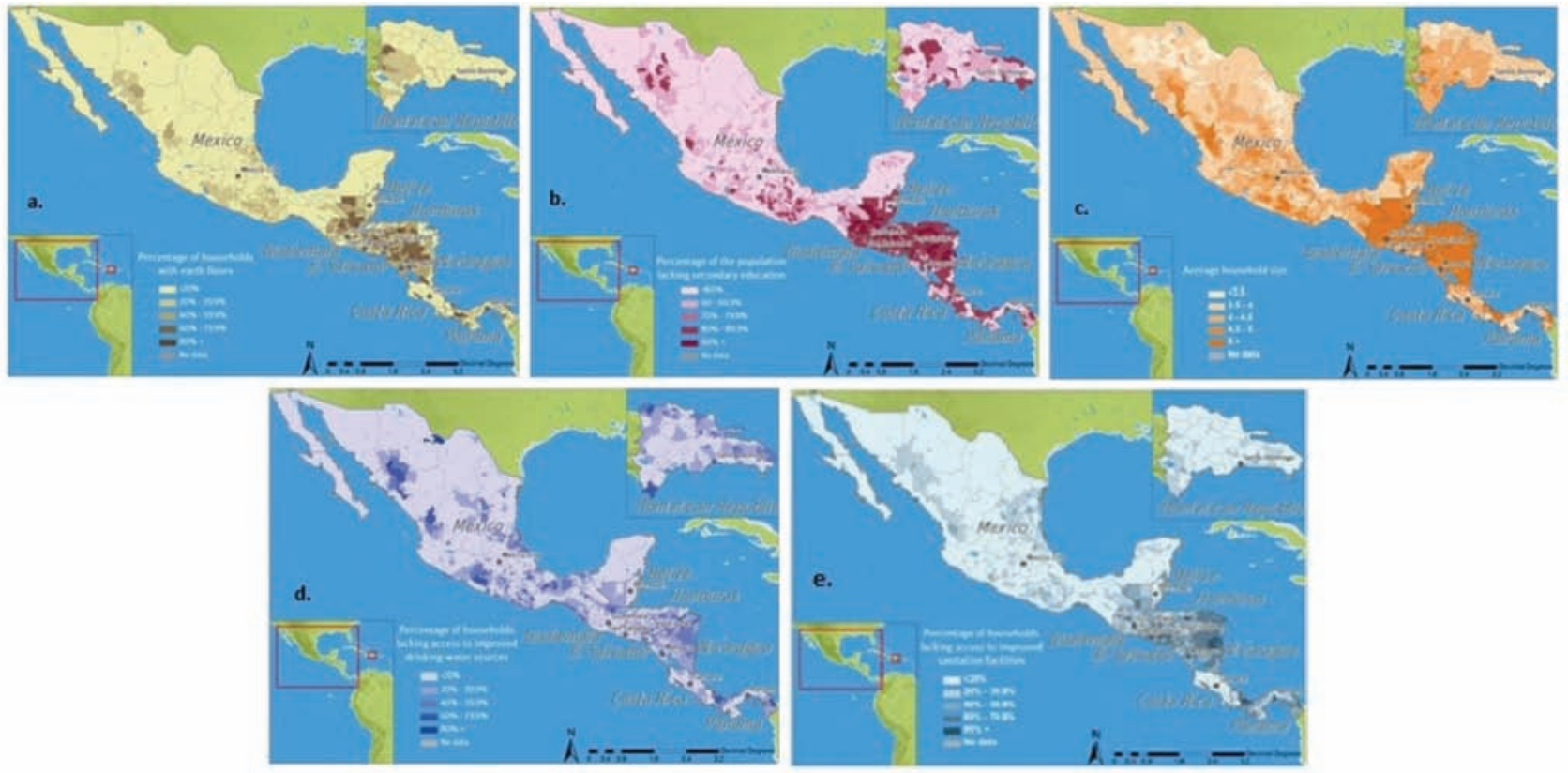

Fig. 5a-e. Distribution of indicators of earth floors (a); lack of education (b); overcrowding (average residents per household) (c); water supply (d); and sanitation (e) at sub-national level in the Central American countries, Mexico and the Dominican Republic. 
mountain range with slightly lower rates along the coast and in the Eastern, sylvatic interior (with the exceptions of some pockets of high rates on the Caribbean coast of Colombia). Average residents per household, on the other hand, seems to run from low to high as one goes from West to East, with the exception of Colombia, which also has high rates along its coasts. The pattern of distribution for the water and sanitation variables is less obvious but seems to lie somewhere between these two patterns.

\section{The Atlantic Countries}

There is a long swathe of what we will call the Atlantic countries $^{11}$ - Brazil, Guyana, Suriname, Trinidad and Tobago (scarcely visible on these maps) and Venezuela for which no data on floor material were available. However, for the other variables, to varying degrees, a pattern is discernible by which the determinants appear highest in the equatorial regions of Brazil and Venezuela and lowest in the more densely populated and urbanised areas of southern Brazil (particularly in the state of São Paolo) and, at least for the water and sanitation variables, coastal Venezuela. Again, this pattern is least stark for the education variable.

\section{The Mesoamerican countries}

For Central America, Mexico and the Dominican Republic, there is a fairly uniform pattern in the distribution of all the indicators, albeit with some minor variations between them. In Mexico there are two foci of high levels of the selected determinants along the Sierra Madre Occidental with more widespread high prevalence in the impoverished Southern states, particularly Guerrero, Oaxaca and Chiapas. However, even in the poorest states of Mexico, the levels of the determinants do not appear as pronounced as they do throughout Central America with the notable exception of the relatively affluent Costa Rica (and, for some indicators,

\footnotetext{
${ }^{11}$ This is a term employed solely for the purposes of this study and does not reflect the country categorization used by either of the institutions with which the authors are affiliated.
}

Belize). This difference is most marked for the education and overcrowding variables and least so for access to water. Panama has low levels of determinants in the centre of the country with much higher rates in its eastern and westernmost extremities (particularly in its indigenous Comarcas). There is no obvious pattern discernible in the distribution of determinants in the Dominican Republic.

\section{Geographical distribution of STH prevalence data points}

Figs. $6 \mathrm{a}$ and $6 \mathrm{~b}$ show the geographical locations of the data points that make up the two STH prevalence variables. The size of the bar corresponds to the level of prevalence recorded in that location. They illustrate the fact that far fewer estimates of STH prevalence have been taken for preschool-aged children (pre-SAC) than for school-aged children (SAC) Furthermore, almost half of the estimates in pre-SAC come from Brazil and of these, the majority are from the coastal states of the South and show considerable variation in prevalence levels. There are data points for pre-SAC from just 10 of the 22 countries included in the study.

The estimates for prevalence in SAC are far more numerous and consequently more representative of the region as a whole. The variable contains estimates from 14 of the countries included in the study but no estimates were available from Chile, Uruguay, Guyana, Suriname, the Dominican Republic, El Salvador, Panama and Trinidad and Tobago. A little over a third of the total data points are from Brazil and almost half of these are from one state (Minas Gerais). There is a dense cluster of high prevalence estimates coming from Central America, specifically Honduras, from which a disproportionate 33 estimates were taken. The two clusters of higher prevalence estimates in Mexico are from the states of Sinaloa and Oaxaca. Nineteen municipalities had estimates for both age groups

\section{Results of the bi-variate analysis}

Simple linear regressions, run in STATA (version 11, Statacorp College Station, Texas) to test the association between each of the five selected determinants and the

Table 3. Summary of STH prevalence indicators.

\begin{tabular}{lccccc}
\hline Indicator & Type of variable & Observations & Mean & $\begin{array}{c}\text { Standard } \\
\text { deviation (SD) }\end{array}$ & Minimum \\
\hline Prevalence estimated in SAC & Proportion & 142 & $33.9 \%$ & 0.24 & $1.0 \%$ \\
Prevalence estimated in pre-SAC & Proportion & 33 & $22.4 \%$ & 0.24 & $0.0 \%$ \\
\hline
\end{tabular}

SAC, school-aged children; pre-SAC, preschool-aged children 

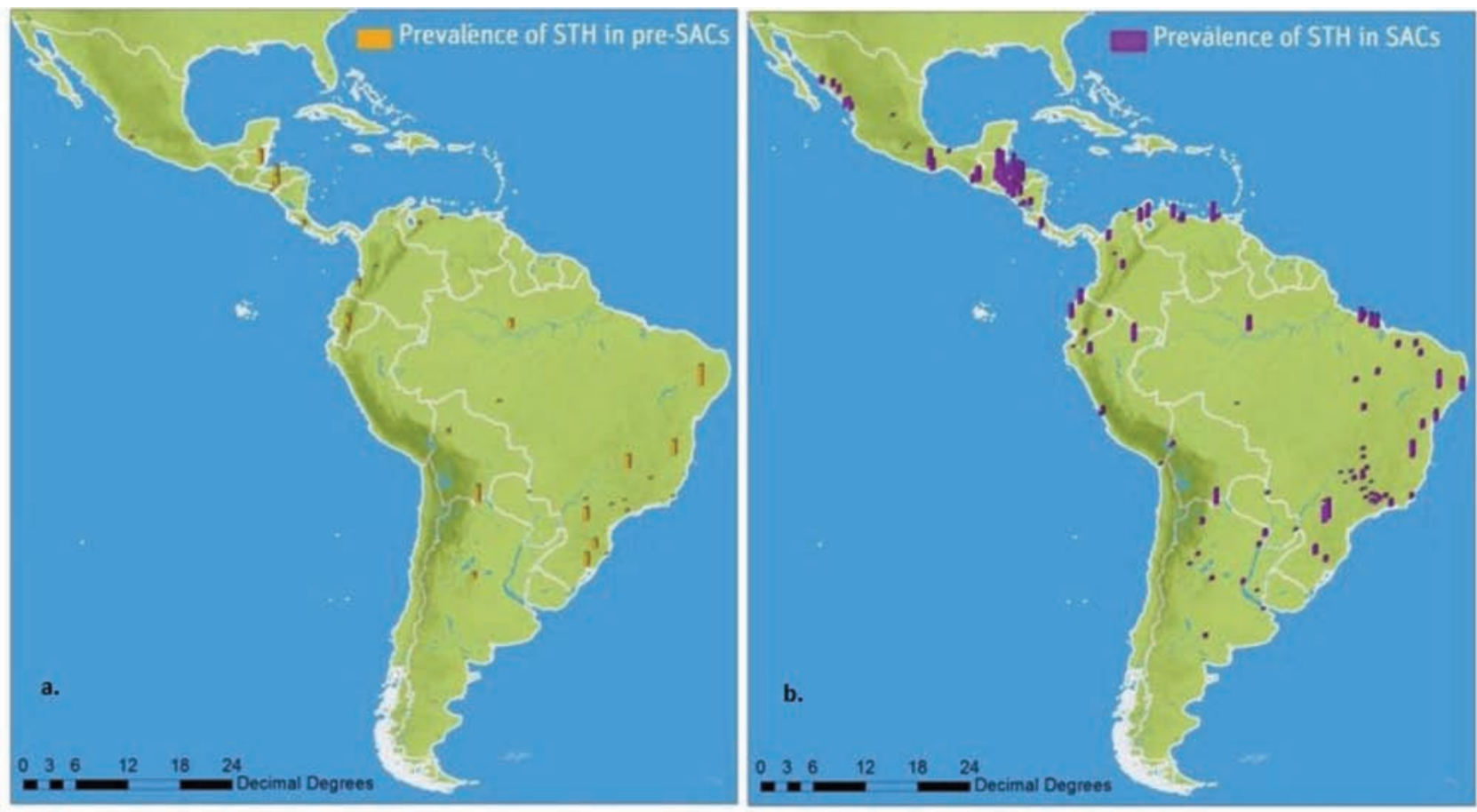

Fig. 6. Geographical location of the STH prevalence estimates included in this study for preschool-aged children (a) and school-aged children (b).

two prevalence variables, resulted in P-values for each of these associations which are shown in Table 4. As is to be expected, the association between the two prevalence variables was highly significant. Furthermore, each of the five variables for the selected determinants were highly significantly associated with each other, lending credibility to the conceptual framework illustrated in Fig. 1, which states that poverty is an underlying determinant of each of the latent variables for which these indicators are proxies. The indicator of prevalence in pre-SAC did not show a statistically significant association with any of the variables for determinants. This is most likely explained by the fact that this variable had so few observations - just 33 . The indicator of prevalence in SAC was associated with the variables for edu- cation, overcrowding and sanitation coverage to a high degree of statistical significance. The association was far less strong (though still just significant at the $5 \%$ level) for earth floors and for water coverage. In the case of earth floors, this is most likely due to the fact that there was no data on this variable for Brazil, by far the largest country in LAC which accounted for almost half $(5,507)$ of the municipalities in the data set and almost a third of the data points for the prevalence variable. In the case of the water coverage variable, the lack of association is harder to explain.

On the basis of these regression results, three variables were subsequently removed from the analysis: STH prevalence in pre-SAC, earth floors and water coverage. In the next stage of the analysis, the remain-

Table 4. P-values for associations between the determinants and prevalence indicators tested by simple linear regression.

\begin{tabular}{lcccccc}
\hline Indicator & Type of variable & Observations & Mean & $\begin{array}{c}\text { Standard } \\
\text { deviation (SD) }\end{array}$ & Minimum & Maximum \\
\hline Prevalence estimated in pre-SAC & $<0.001$ & 0.114 & 0.200 & 0.175 & 0.135 & 0.198 \\
Earth floors & 0.040 & $<0.001$ & $<0.001$ & $<0.001$ & $<0.001$ & \\
Education & $<0.001$ & $<0.001$ & $<0.001$ & $<0.001$ & \\
Overcrowding & $<0.001$ & $<0.001$ & $<0.001$ & & \\
Water & 0.024 & $<0.001$ & & & \\
\hline Sanitation & $<0.001$ & & & & \\
\hline
\end{tabular}


Table 5. Weights applied to indicators in aggregating the risk index.

\begin{tabular}{ll}
\hline Indicator & Weight \\
\hline Overcrowding & 0.067 \\
Lack of education & 0.1 \\
Sanitation & 0.2 \\
\hline
\end{tabular}

ing variables for the determinants were aggregated into a single index in order to capture as much as possible of the socio-economic determinants that determine the risk of STH infection. However, not all of the determinants can count equally towards this index, because they contribute in different degrees towards the outcome - some factors are more proximate than others. Therefore, the determinants needed to contribute to the aggregate indicator in a way that is proportional to their relative proximity within the conceptual framework. Sanitation access needed to be given a greater weight than lack of education which in turn should have a greater weight than overcrowding. An additional problem is that the overcrowding variable is continuous, running from 2.57 to 9.41 , while the other two variables are proportions between 0 and 1. The overcrowding variable therefore needed to be weighted even further so that it didn't contribute a disproportionately high amount to the final index. Table 5 shows the weights that were eventually applied to the indicators in aggregating the final index. Overcrowding is weighted in such a way that, though the weight it's assigned is lower than that for education, once all the observations are adjusted by it, the variable's contribution to the final index will be between that of sanitation coverage and that of education. Table 6 describes the STH risk index that resulted from multiplying the values for the observations in each of the three variables by their corresponding weights and summing the results. Even though all of its values lie between 0 and 1 it is not a proportion.

Fig. 7 shows the geographical distribution of the STH risk index at sub-national level in LAC. What is most striking about the map is that there are several clear bands of high-risk municipalities - one along the
Amazon basin, incorporating parts of Bolivia, Brazil, Colombia, Ecuador and Venezuela and one in the more remote regions of the Central American countries of Guatemala, Honduras, Nicaragua and Panama (areas characterised by large populations of indigenous groups). In addition to these, there are outlying pockets of high-risk in coastal Colombia, Andean Ecuador, in the Gran Chaco region of eastern Bolivia and in Paraguay. In many ways these results are unsurprising as they conform to what is known about the distribution of poverty more generally in the region. Those areas that come out as at high-risk in this model are those that have marginalised populations that experience a lack of access to services. This confirms that STH is indeed a disease of poverty and it lends credibility to the conceptual model for the analysis, according to which, the determinants included in the study are themselves determined by poverty.

Next the association between the STH risk index and the observed (published) prevalence estimates was tested using a simple linear regression in order to validate the index and provide inputs for the prevalence model. The results of this test are shown in Table 7 and show a high level of statistical significance for the association.

Fig. 8 shows the predicted STH prevalence estimates plotted against the corresponding value of the STH risk index for those municipalities with the linear regression line and upper and lower confidence intervals. The distribution of the data points on this chart do not immediately suggest a strong association and imply that caution must be exercised when interpreting the results.

\section{Results of the prevalence model}

Finally, in order to model the prevalence of STH, the coefficient and constant from the results of the regression for the association between the STH risk index and the published estimates was put into the regression equation, which predicted the STH prevalence $y$ as follows:

$$
\mathrm{y}=\alpha+\beta x
$$

Table 6. Summary of STH risk index and predicted STH prevalence variables.

\begin{tabular}{|c|c|c|c|c|c|}
\hline Indicator & Observations & Mean & $\begin{array}{c}\text { Standard } \\
\text { deviation (SD) }\end{array}$ & Minimum & Maximum \\
\hline STH risk index & 12,188 & 0.41 & 0.09 & 0.19 & 0.78 \\
\hline Predicted STH prevalence & 12,188 & $32.9 \%$ & 0.09 & $9.0 \%$ & $71.9 \%$ \\
\hline
\end{tabular}


Table 7. Results of simple linear regression to test the association between the aggregated STH risk index and the published STH prevalence estimates.

\begin{tabular}{|c|c|c|c|c|c|c|c|c|c|}
\hline \multirow{2}{*}{ P-value } & \multirow{2}{*}{$\mathrm{R}^{2}$} & \multicolumn{4}{|c|}{ Coefficient } & \multicolumn{4}{|c|}{ Constant } \\
\hline & & Value & P-value & Lower CI & Upper CI & Value & $\mathrm{P}$-value & Lower CI & Upper CI \\
\hline$<0.001$ & 0.199 & 1.355 & $<0.001$ & 0.900 & 1.809 & 0.046 & 0.391 & -0.059 & 0.150 \\
\hline
\end{tabular}

where $\alpha=0.046, \beta=1.355$ and $x=$ STH risk index. This formula was applied to the value of the risk index for each of the municipalities in the dataset in order to derive an estimate of the STH prevalence in each one. The resulting predicted STH prevalence variable is described in Table 6 . The frequency distribution of the predicted STH prevalence variable for the municipalities in the data set is shown in Fig. 9. The distribution is markedly narrow and skewed very slightly towards the higher prevalence levels. The World Health Organization (WHO) recommends classifying communities as high-risk if they have an STH prevalence of greater than $50 \%$ and low-risk if the prevalence is between $20 \%$ and $50 \%$ (WHO, 2007). According to this schema, it's possible to see that there are relatively few municipalities that would count as not being at any level of risk according to the estimates predicted by the model and therefore MDA would be the recommended intervention throughout virtually the entire region. Conversely, there are relatively few municipalities that would be classified as high-risk and requiring two annual rounds of MDA.

In Fig. 10 the prevalence rates predicted by the model are mapped onto the region and classified according to the risk categories and corresponding treatment strategies recommended by the WHO. It shows that in every country there are municipalities that would require MDA at least once a year, but in

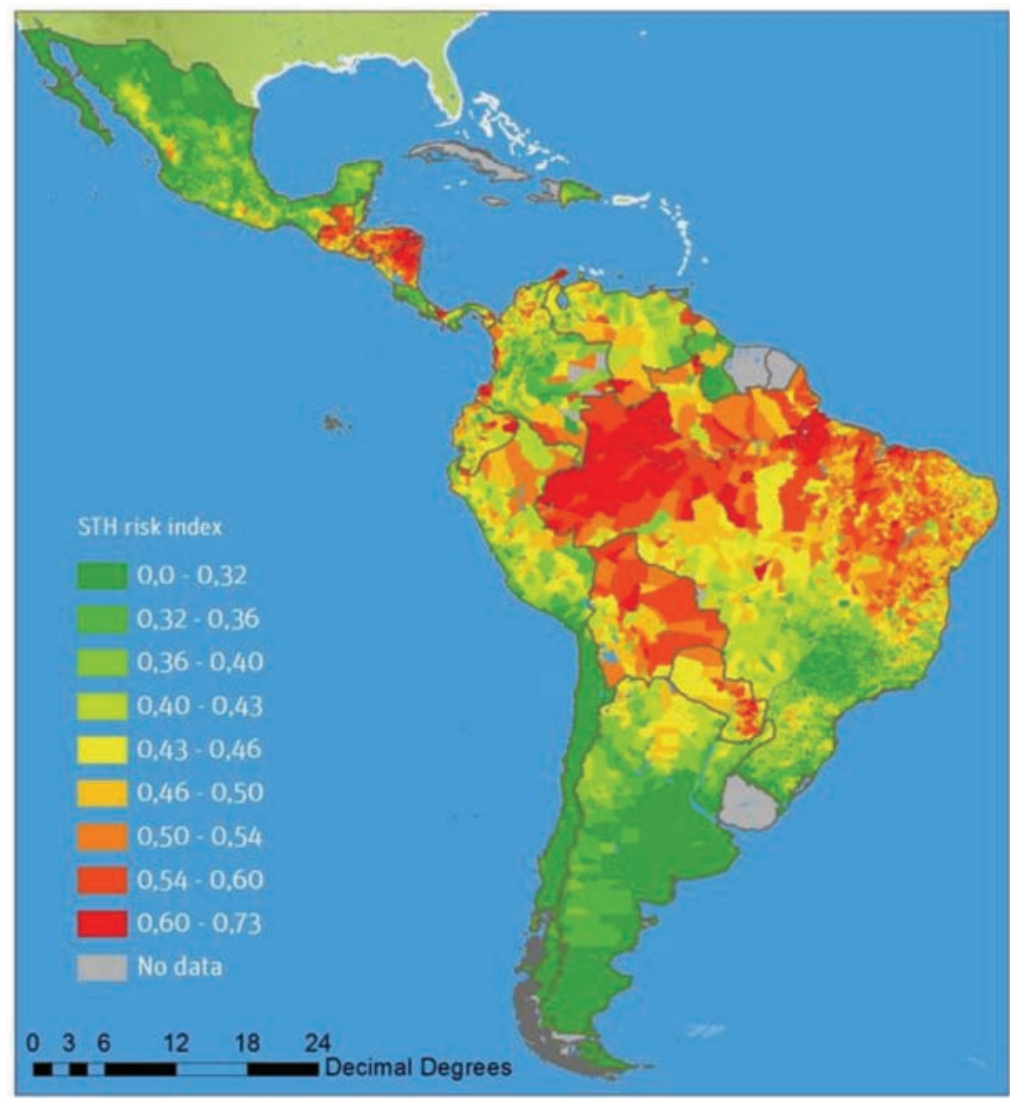

Fig. 7. Distribution of STH risk index at sub-national level in LAC. 


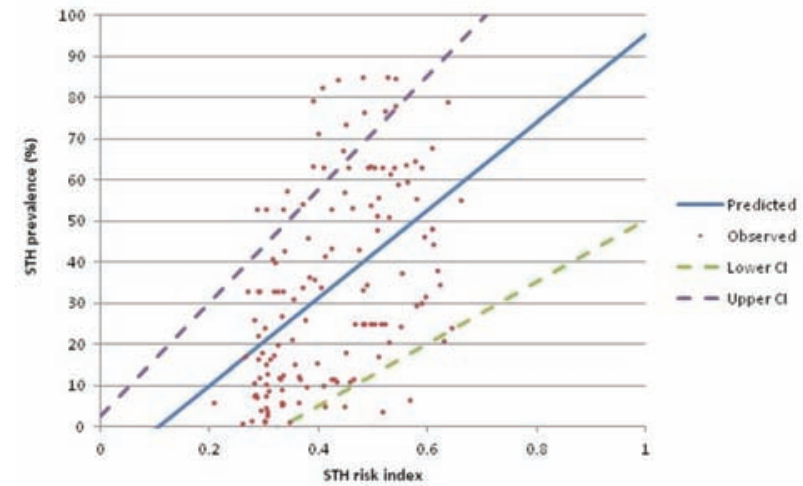

Fig. 8. Predicted STH prevalence estimates plotted against the STH risk index with regression line and upper and lower 95\% confidence intervals (CIs).

seven countries, there are no municipalities requiring biannual MDA (Argentina, Belize, Chile, Costa Rica, the Dominican Republic, Guyana and Trinidad and Tobago). Both Peru and Venezuela contain just one such municipality each (the one in Peru is in the region of Loreto not visible on this map), while in Mexico, the high-risk area is confined to just one small area in the state of Oaxaca.

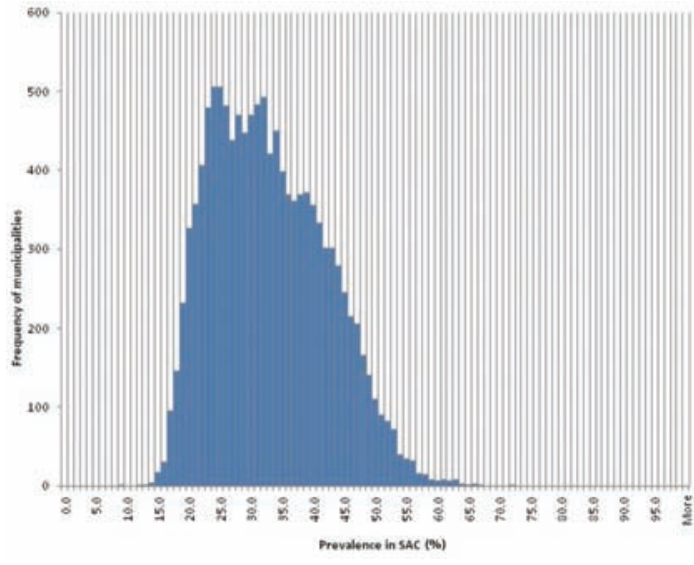

Fig. 9. Frequency distribution of the STH prevalence predicted by the model for the municipalities in the data set (single percentiles).

\section{Estimates of requirements for $M D A$}

The next step in the study was to estimate, given the predicted prevalence of STH, the requirements in terms of financial and other inputs that would be necessary in order to treat the populations of the countries included in the study according to the WHO recommendations. It was possible to calculate the num-

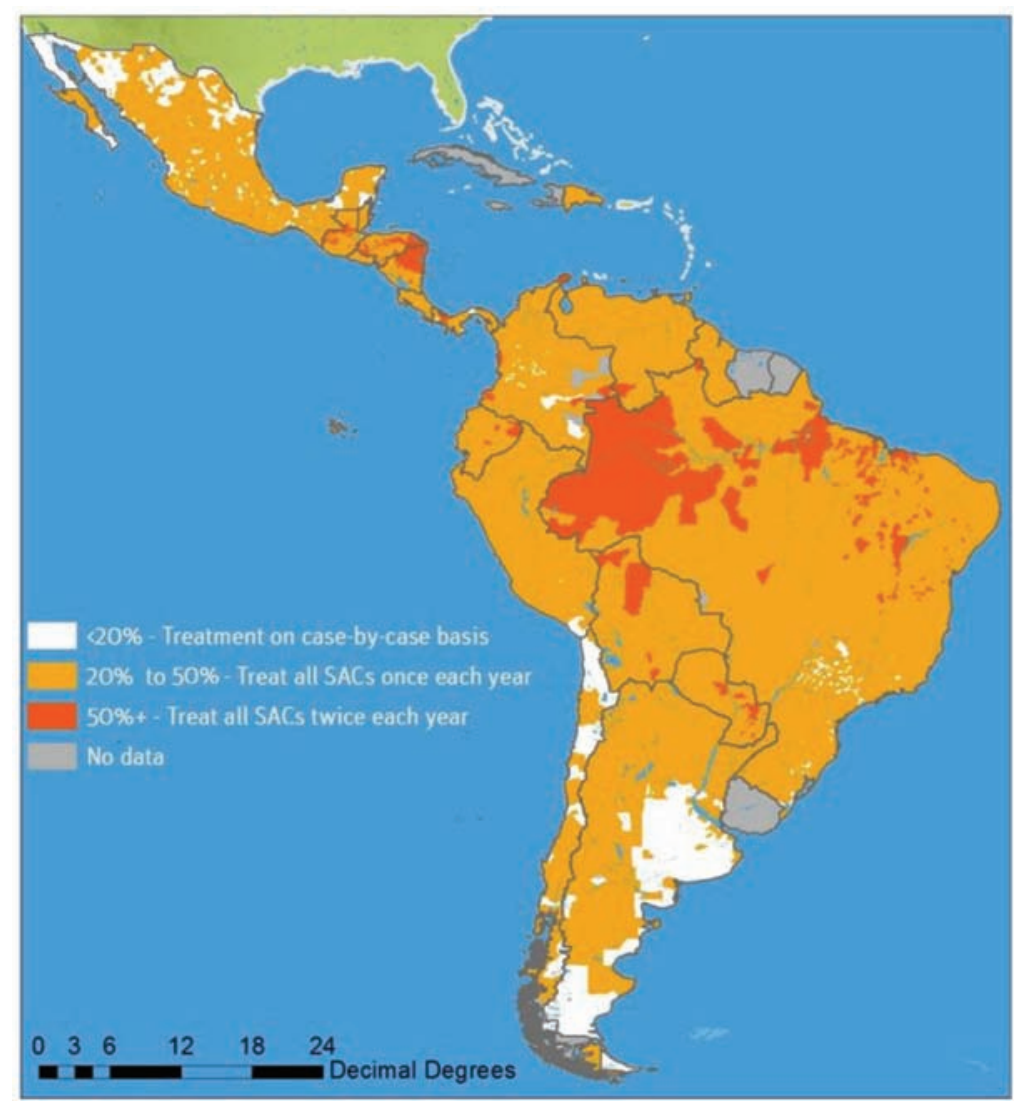

Fig. 10. Modeled prevalence of STH classified by WHO risk categories. 
ber of MDA rounds that would be required annually in each municipality by applying the thresholds for the treatment categories given by the WHO to the prevalence rates predicted by the model. Municipalities were treated as implementation units for MDA such that those with a predicted prevalence of higher than $50 \%$ would require two rounds of MDA annually and those with prevalence $20-50 \%$, just one ${ }^{12}$. We then took data from the censuses on the number of SAC (individuals aged 5-14 years) in each municipality in the database and multiplied that by the number of annual MDA rounds required to arrive at the number of doses of PCT required for MDA annually. We also calculated the estimated number of cases of STH by applying the projected prevalence rate to the number of SAC which, although not strictly relevant for planning MDA, could be a useful figure for advocacy purposes. Calculating the cost of procuring sufficient albendazole for all of the MDA campaigns was then a simple question of applying the unit cost for a single dose to the number of PCT doses required. Guyatt and others found that the price for a $400 \mathrm{mg}$ dose of albendazole is between US\$ 0.020 and 0.037 (Guyatt, 2003). The more recent estimate of US\$ 0.02 from Montresor and others (endorsed by the WHO in its most recent deworming guidelines) is consistent with this and with the fact that the cost of anthelminthic drugs has declined over the period since the Guyatt study was carried out (Montresor et al., 2010). We therefore took the value of $\$ 0.02$ and applied it to the number of PCT doses required. In addition to the cost of procuring drugs for PCT, it was also necessary to estimate the costs of delivering the drugs through a school-based MDA programme (i.e. the programme costs such as training of drug distrib-

\footnotetext{
${ }^{12}$ This assumes that all no municipalities had implemented deworming previously. In reality, if a program has implemented deworming for more than 5 or 6 years (as is the case for Mexico and Nicaragua, for example), then the thresholds for implementation are different depending on the levels of prevalence found after deworming. The WHO guidelines also recommend that, in implementation units with a prevalence of less than $20 \%$, STH be treated on a case-by-case basis. It would therefore be possible using this model, to calculate the number of PCT doses that would be needed by the health system if every child with STH were to be diagnosed and treated. However, since the purpose of this study is to calculate the requirements for mass drug administration, we took the decision not to include in the calculations, PCT requirements for municipalities that do not meet the $20 \%$ threshold for intervention with MDA. STH infections are a problem at community level rather than in individual issue, treating individual cases cannot be expected to have an impact in areas where it is not considered a public health problem. Furthermore, drug donation programmes at global level
}

utors, equipment, staff allowances, etc.). For this we took the average unit cost of US\$ 0.58 that was used by Bitrán and others in a previously published costing study (a figure that had been adjusted for each country's gross domestic product at purchasing power parity using a linear model) (Bitrán et al., 2009)13. To arrive at the total annual costs of an STH control programme for each municipality, the cost of the PCT drugs was added to the delivery costs. These cost estimates were summed for each country in the study. In addition, it was possible to calculate the estimated national prevalence of STH in SAC by summing the number of cases and the number of SAC for each country and using the former as the numerator and the latter as the denominator.

The results for this stage of the analysis are presented in Table 8. It is important to remember that the national STH prevalence rates apply only to the SAC population and were calculated taking the sum of the SAC in all municipalities in that country as the denominator and the total estimated number of STH cases in all municipalities in that country as the numerator. As with the results at sub-national level, the distribution of the resulting variable is narrow with the lowest being Trinidad and Tobago at $19.3 \%$ - putting the country as a whole just below the $20 \%$ threshold for intervention with MDA of PCT - and the two highest being Guatemala and Honduras at $41.8 \%$ meaning that no country in the study when taken as a whole falls within the-high risk category. The model predicts that slightly fewer than 30 million SAC in LAC are infected with STH (which itself is an underestimation as it is the sum of the people in that age range reported in different countries' censuses in different years), i.e. $28 \%$ of the total population in that age range. The

(albendazole and mebendazole) are focused on supporting MDA campaigns and not individual treatment.

${ }^{13}$ Montresor at al. (2010) estimate a far lower figure of US\$ 0.033 (range US\$ 0.012-0.060) for the financial costs of delivering deworming. However, we opted for the much more conservative Bitran estimate, which has the advantage of having been adjusted for Gross Domestic Product at Purchasing Power Parity (GDP PPP), because the countries from which the Montresor estimates are derived are all either low- or lower-middle-income, none of which are in LAC. One would expect the prices of the labour and inputs for training of personnel, drug transport, social mobilization and monitoring in LAC to be higher than in south east Asia and Africa. Furthermore, several of the programmes from which Montresor and colleagues draw their data are from campaigns that reached between 1 and 2.9 million children and therefore had the advantage of economies of scale. Since this model assumes drug delivery at municipal level targeting numbers of children mostly in the thousands or tens of thousands, the same economies of scale may not be available. 
Table 8. Predicted STH prevalence in SAC and requirements for MDA campaigns by country.

\begin{tabular}{|c|c|c|c|c|c|c|c|c|c|}
\hline Row labels & $\begin{array}{l}\text { Estimated } \\
\text { prevalence }\end{array}$ & $\begin{array}{c}\text { Number of } \\
\text { SAC }^{a}\end{array}$ & STH cases & $\begin{array}{l}\text { SAC eligible } \\
\text { for } \mathrm{MDA}^{\mathrm{b}}\end{array}$ & $\begin{array}{c}\text { MDA } \\
\text { campaigns }^{c}\end{array}$ & $\begin{array}{l}\text { Doses } \\
\text { required }\end{array}$ & $\begin{array}{l}\text { Drug } \\
\text { costs }^{d}\end{array}$ & $\begin{array}{l}\text { MDA costs } \\
(\text { US\$) })^{\circ}\end{array}$ & $\begin{array}{l}\text { Total MDA } \\
\text { cost (US\$) }\end{array}$ \\
\hline Argentina & $22.6 \%$ & $6,898,410$ & $1,555,947$ & $4,274,435$ & 352 & $4,274,435$ & 128,233 & $2,479,172$ & $2,607,405$ \\
\hline Belize & $30.7 \%$ & 38,079 & 11,703 & 38,079 & 6 & 38,079 & 1,142 & 22,086 & 23,228 \\
\hline Bolivia & $36.2 \%$ & $2,110,517$ & 763,935 & $2,110,517$ & 121 & $2,155,164$ & 55,942 & $1,249,995$ & $1,305,937$ \\
\hline Brazil & $29.8 \%$ & $33,926,441$ & $10,119,516$ & $28,263,868$ & 5,617 & $29,210,348$ & 584,207 & $16,942,002$ & $17,526,209$ \\
\hline Chile & $19.5 \%$ & $2,739,050$ & 534,258 & $1,142,234$ & 30 & $1,142,234$ & 22,845 & 662,496 & 685,340 \\
\hline Colombia & $26.0 \%$ & $8,616,811$ & $2,244,307$ & $5,673,140$ & 1,099 & $5,761,998$ & 115,240 & $3,341,959$ & $3,457,199$ \\
\hline Costa Rica & $23.3 \%$ & 840,223 & 195,954 & 746,870 & 76 & 746,870 & 14,937 & 433,185 & 448,122 \\
\hline Dominican Rep. & $23.9 \%$ & $1,676,269$ & 400,942 & $1,524,618$ & 224 & $1,524,618$ & 30,492 & 884,278 & 914,771 \\
\hline Ecuador & $31.1 \%$ & $2,703,160$ & 841,113 & $2,703,160$ & 226 & $2,717,134$ & 54,343 & $1,575,938$ & $1,630,280$ \\
\hline El Salvador & $36.1 \%$ & $1,218,791$ & 439,389 & $1,162,090$ & 273 & $1,190,148$ & 23,803 & 690,286 & 714,089 \\
\hline Guatemala & $41.8 \%$ & $3,101,616$ & $1,297,806$ & $3,101,616$ & 387 & $3,654,466$ & 73,089 & $2,119,590$ & $2,192,680$ \\
\hline Guyana & $24.0 \%$ & 178,157 & 42,814 & 178,157 & 10 & 178,157 & 3,563 & 103,331 & 106,894 \\
\hline Honduras & $41.8 \%$ & $1,678,228$ & 701,741 & $1,678,228$ & 397 & $1,985,245$ & 39,705 & $1,151,442$ & $1,191,147$ \\
\hline Mexico & $22.8 \%$ & $21,987,420$ & $5,014,155$ & $12,474,570$ & 2,130 & $12,483,261$ & 249,665 & $7,240,291$ & $7,489,957$ \\
\hline Nicaragua & $41.5 \%$ & $1,323,301$ & 548,725 & $1,323,301$ & 183 & $1,589,766$ & 31,795 & 922,064 & $\$ 953,860$ \\
\hline Panama & $26.4 \%$ & 669,606 & 176,931 & 387,137 & 74 & 444,844 & 8,897 & 258,010 & $\$ 266,906$ \\
\hline Paraguay & $37.2 \%$ & $1,213,738$ & 451,677 & $1,213,738$ & 249 & $1,334,811$ & 26,696 & 774,190 & $\$ 800,887$ \\
\hline Peru & $28.6 \%$ & $5,632,913$ & $1,612,237$ & $5,488,885$ & 191 & $5,504,074$ & 110,081 & $3,192,363$ & $3,302,444$ \\
\hline Trinidad and Tobago & $19.3 \%$ & 206,119 & 39,750 & 80,706 & 8 & 80,706 & 1,614 & 46,809 & 48,424 \\
\hline Venezuela & $29.4 \%$ & $5,164,481$ & $1,517,907$ & $5,095,668$ & 332 & $5,095,822$ & 101,916 & $2,955,577$ & $3,057,493$ \\
\hline Total & $28.0 \%$ & $101,923,330$ & $28,510,806$ & $78,661,017$ & 11,985 & $81,112,180$ & $1,678,208$ & $47,045,064$ & $48,723,272$ \\
\hline
\end{tabular}

${ }^{a}$ As reported in the most recent census

'SAC living in municipalities with a prevalence of STH greater than $20 \%$

'Number of municipal level rounds of MDA required annually

${ }^{\mathrm{d}}$ Assuming a unit cost of US\$ 0.0285 per dose of PCT average of values found in Guyatt (2003)

${ }^{e}$ Assuming a unit cost of US\$ 0.58 per MDA round (i.e. per PCT dose delivered) (Bitrán et al., 2009).

model predicts an annual cost for the procurement of PCT of around US\$ 1.7 million and a total cost of US\$ 47 million for implementing a full MDA program for STH control programme according to the WHO guidelines throughout the entirety of the countries included in the study.

It is worth comparing the results of this model to that of other published models. The WHO estimates the total number of SAC requiring PCT in the Americas as $31,405,298$ compared to 78,661,017, a number more than two and a half times higher predicted by this model (WHO, 2011). This discrepancy may be due to differences in the methodologies of the two studies. The WHO estimates were established based on applying several criteria, mainly using the proportion of SAC without access to improved sanitation facilities and taking into account differences between rural and urban areas as well as availability of prevalence data. Fig. 11a compares the national level STH prevalence predicted by this model to those presented by Hall et al. (2009) (which are those origi- nally arrived at by de Silva et al. (2003) after applying to updated data the methodology originally employed by Chan et al. (1994)). The figure reveals that the two methodologies result in a similar ranking by prevalence of the countries. Both place Guatemala as at the top of the ranking and Trinidad and Tobago at the bottom and, while there are some significant differences in where in the ranking the methodologies place the countries in between (Nicaragua, Dominican Republic and Chile for example), there seems to be broad similarities in the trend. However, the range of prevalence values in the Hall et al. (2009) is much wider - ranging from (a perhaps implausibly high) $92.6 \%$ in Guatemala to $4.5 \%$ in Trinidad and Tobago. Our model predicts a more homogenous situation across the countries.

Fig. 11b compares the total costs for delivering MDA to the SAC population as predicted by this model with those presented in Bitrán et al. (2009). A full comparison country by country is not possible because several included in this model were left out of 

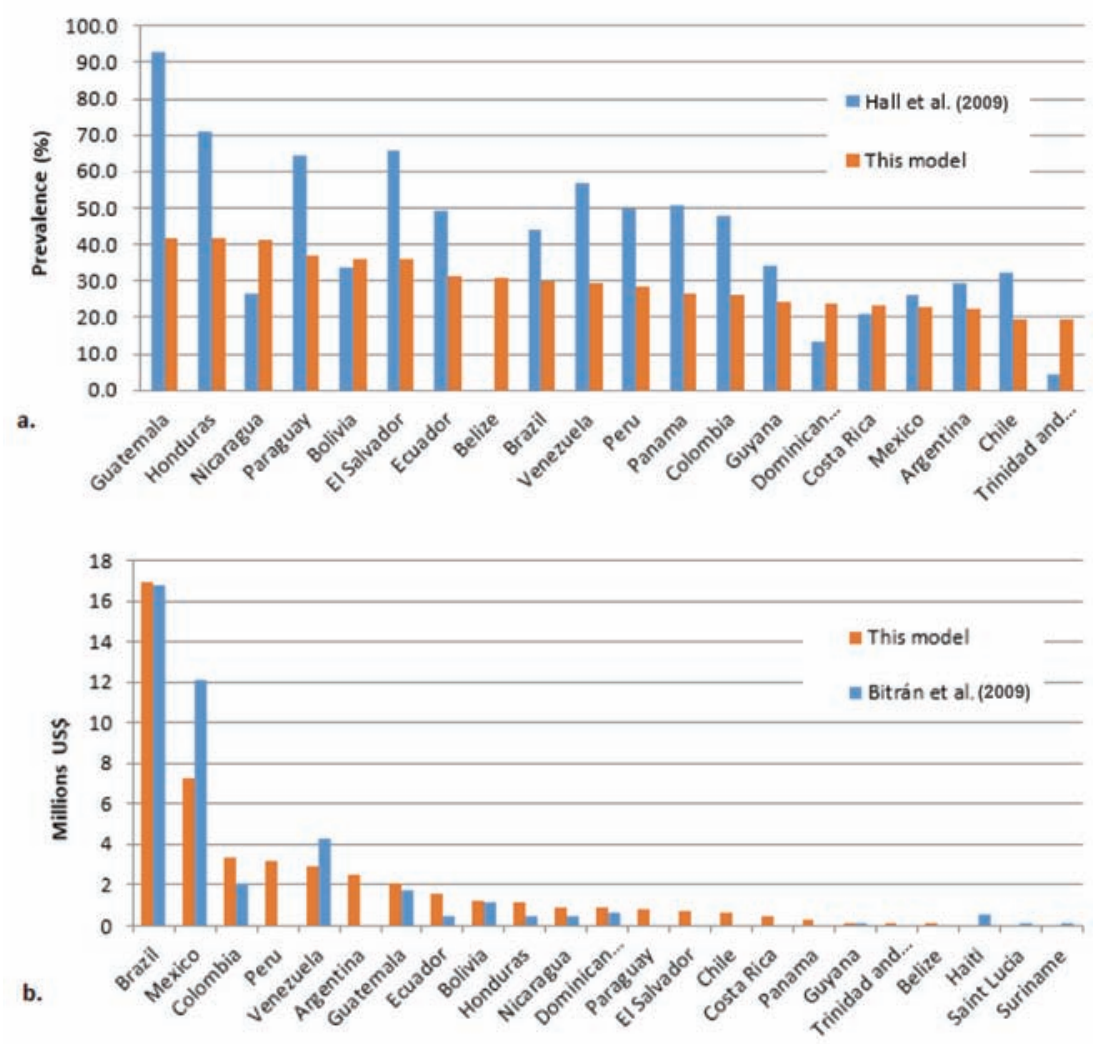

Fig. 11. Comparison of national level STH prevalence (a) and MDA delivery costs (b) predicted by this model compared with results from other published models (Bitrán et al., 2009; Hall et al., 2009).

the other and vice versa (Haiti, Saint Lucia and Suriname were included in the Bitrán model). As mentioned above, these estimates were derived by applying to the population at risk a unit cost for PCT delivery that were based on the cost menu presented in Guyatt (2003) and adjusted by country using GDP PPP and a linear model (Bitrán et al., 2009). The total costs for the region calculated by the two models were similar US $\$ 40,837,418$ calculated by Bitrán and others, compared with US $\$ 48,723,272$ by this model. However, the breakdown of these figures by country shows that, while the two models produced almost an identical cost estimate for Brazil and Bolivia, there were considerable discrepancies between the other countries. This model predicts almost half the cost for Mexico, two thirds of the costs for Venezuela and considerably higher costs for Colombia, Ecuador, Honduras and Nicaragua than the other.

\section{Discussion}

A study of this scope is prone to many limitations which restrict the interpretation of the results and the uses to which its findings may be put. Here, we list some of these considerations.

\section{The timing of the data}

Many of the censuses from which the indicators of the determinants selected were derived date back over 10 years. The past decade has seen great strides in economic development in LAC with corresponding improvements in the living conditions of and the provision of services to the region's population. Therefore, the indicators, and by extension the risk index and prevalence estimates, represent an overestimate of the current situation regarding STH transmission and its determinants. Several of the countries have conducted new censuses since the ones used in the study. However, at the time of writing, the data from these are not publicly available at the level of detail required for this analysis. Furthermore, the censuses of the various countries span a period of 10 years (from Belize's and Trinidad and Tobago's in 2000, to Mexico's and Panama's in 2010). This has implications for the comparability of the determinant data between countries since they refer to different years. Similarly, the prevalence data estimates that made up the other variable in the regression analysis span a period of 15 years from 1995 to 2009 . However, it was necessary to take data points from such a wide time period in order to have enough observations in the data set to run the regression. 
Potential biases in prevalence data

A key assumption of the model is that the data points that make up the STH prevalence variable are taken from sites that are representative both of the municipality in which that site is located and of the region as a whole. This assumption is easily challenged. It is extremely unlikely that all of the prevalence data points in the set were derived through methodologies that were explicitly designed to derive a representative estimate of STH prevalence at municipal level. What is more likely is that most, if not all of them, were carried out in particular areas and communities within that municipality. LAC is a region of considerable inequality where poverty and affluence can be found side by side. Even within the same municipalities, there can be big differences in some of the factors that determine the risk of STH infection. Furthermore, there is no reason to suggest that the sites where the prevalence estimates were taken were selected randomly. What's more likely is that many of them were selected either for convenience (proximity to a research institute or university, for example) or due to there already being reason to suspect that STH prevalence was a public health concern there. This would add considerable selection bias to the sample.

\section{Missing data for priority countries}

As already mentioned, five countries were excluded from the study due to the necessary data not being available. Two of these, Suriname and Haiti, are in the first of four priority groups proposed by PAHO with regard to NTDs ${ }^{14}$ and are thought to have the kind of poor sanitation and living conditions that are conducive to STH transmission (particularly Haiti post-2010 earthquake). With these countries excluded, the model fails to give a complete picture of the STH situation and burden in the region.

\section{Failure to account for ecological and climate data}

STH transmission is heavily dependent on certain ecological and climatic conditions. The rates of development and survival of free-living infective stage parasites are influenced by factors such as temperature relative atmospheric humidity and soil moisture that prevail in the surrounding environment (Brooker et al., 2002, 2006). It is thought, for example, that the development of $A$. lumbricoides and T. trichiura ceases to be viable outside of a temperature range of $5-38^{\circ} \mathrm{C}$, as this is what has been observed under experimental conditions (Brooker et al., 2006). It is likely, therefore, that some areas of Latin America that are particularly arid or prone to extreme temperatures might be unsuitable to sustain transmission of STH (for example at high altitudes in the Andean regions of Peru and Bolivia). Clearly, a model that relies solely on socio-economic data is unable to capture these other determinants of transmission. A next step for the study would be to identify those municipalities that have an average temperature or humidity that is above or below the range in which STH development and survival is viable, so that those municipalities can be excluded from the calculation. A further problem with this approach is that ecological conditions may not be uniform within a single municipality. Geospatial analysis of climate, temperature and ecological variables is usually conducted using satellite data at the level of the pixel, and not at municipality level ${ }^{15}$.

\section{Strength of the association}

As already highlighted in the Results section and illustrated in Fig. 7, although the P-value for the regression of the STH risk index against the STH prevalence variable suggests a strong statistical association between the two, when the one is plotted against the other in a scatter chart, the strength of this association is not obvious.

\section{Assumption of full school enrolment}

The costs of delivering MDA calculated here represent estimates for school-based deworming programmes, yet the population in need is defined as the entire school-aged population in the municipality. The model therefore makes the implicit assumption that $100 \%$ of the school-aged children are enrolled in the school system and can be reached through this delivery channel. This does not reflect the reality in many countries of LAC where the percentage of SAC enrolled in school can be lower than $60 \%$. However, the results should be interpreted as the upper bound of a range of cost estimates that uses the entire eligible population in its calculation (rather than the reachable population). After all, a child's eligibility for deworming is determined solely by their age and the STH

\footnotetext{
${ }^{14}$ It should be pointed out that the health authorities in Suriname completed a survey of STH and schistosomiasis infection in school-aged children (SAC) across six coastal districts of the country and the inland district of Brokopondo in 2011. The results showed very low prevalence rates, far below the $20 \%$ threshold for mass intervention. In due course they will implement a survey in the three remaining districts not included in the first survey to determine whether MDA is required anywhere in the country.

${ }^{15} \mathrm{As}$ in the recent article by Chammartin et al.
} 
prevalence in the community in which they live, and not by their school-enrolment status or whether or not they are reachable by the particular delivery channel by which the deworming is distributed.

Given the considerable restrictions identified in this section, it is clear that the results from the tool presented here may only be reliably used in a very limited number of situations. It would not be appropriate, for example, to base programmatic decisions solely on the results of this model, and no model should ever be used as a substitute for an empirical prevalence assessment. However, in spite of these limitations, we are of the opinion that the tool presented here does have many potential practical applications. One of these would be in advocacy. The fact that this model predicts an annual cost of less than US\$ 50 million to implement MDA campaigns as part of STH control programs throughout the entire region. (and that this estimate is lent credibility by being in the same order of magnitude as previously published estimates), has the potential to contribute towards galvanizing the public health and donor communities towards taking steps to tackle the issue. In addition, there are several ways in which these total costs might be further reduced. For example, if all the countries in the study were to take full advantage of existing albendazole or mebendazole donation programme, the total cost for the region could be reduced by US $\$ 1.7$ million. Similarly if national programmes were to capitalise on opportunities to integrate deworming activities into other health service deliver platforms operational costs could be reduced. The model assumes a top-down, vertical control programme of the kind recommended by the WHO. However, if STH interventions were to be embedded in existing programmes (as indeed they are in several countries in LAC), such as primary health care, integrated management of childhood illness, child health weeks, vaccination or nutrition campaigns, etc., considerable savings could accrue. The cost estimates presented here could ultimately be adjusted downward owing to economies of scale through the integration of STH control within the wider national health care systems. It would be challenging to build these kind of cost-saving considerations into the model, however, the fact that the model does break down the total costs into two components - drug costs and operational/delivery costs allows for them to be adjusted separately in order to reflect scenarios like these.

Furthermore, the advantage that this model has over previous attempts is that the estimates can be broken down to national and sub-national level. As we have shown, there is a scarcity of reliable empirical data on

Table 9. Example of applying the tool to calculate values for municipalities targeted for Inter-American Development Bank (IDB) projects.

\begin{tabular}{|c|c|c|c|c|c|c|c|}
\hline $\begin{array}{l}\text { Administrative unit } \\
\text { targeted for project }\end{array}$ & $\begin{array}{l}\text { Number of } \\
\text { SAC }\end{array}$ & STH cases & $\begin{array}{c}\text { MDA } \\
\text { campaigns }\end{array}$ & $\begin{array}{l}\text { PCT doses } \\
\text { required }\end{array}$ & $\begin{array}{l}\text { Cost of PCT } \\
\text { (US\$) }\end{array}$ & $\begin{array}{l}\text { Cost of MDA } \\
\text { (US\$) }\end{array}$ & $\begin{array}{c}\text { Total control } \\
\text { cost (US\$) }\end{array}$ \\
\hline Brazil & 434,659 & 119,798 & 3 & 434,659 & $8,693.18$ & $252,102.22$ & $260,795.40$ \\
\hline Pernambuco & 434,659 & 119,798 & 3 & 434,659 & $8,693.18$ & $252,102.22$ & $260,795.40$ \\
\hline Jaboatão dos Guararapes & 114,136 & 34,199 & 1 & 114,136 & $2,282.72$ & $66,198.88$ & $68,481.60$ \\
\hline Olinda & 66,324 & 18,721 & 1 & 66,324 & $1,326.48$ & $38,467.92$ & $39,794.40$ \\
\hline Recife & 254,199 & 66,877 & 1 & 254,199 & $5,083.98$ & $147,435.42$ & $152,519.40$ \\
\hline Guatemala & 314,342 & 148,464 & 42 & 381,224 & $7,624.48$ & $221,109.92$ & $228,734.40$ \\
\hline Alta Verapaz & 224,162 & 106,684 & 20 & 268,533 & $5,370.66$ & $155,749.14$ & $161,119.80$ \\
\hline Sololá & 90,180 & 41,780 & 22 & 112,691 & $2,253.82$ & $65,360.78$ & $67,614.60$ \\
\hline Guyana & 68,773 & 14,391 & 1 & 68,773 & $1,375.46$ & $39,888.34$ & $41,263.80$ \\
\hline Region 4 & 68,773 & 14,391 & 1 & 68,773 & $1,375.46$ & $39,888.34$ & $41,263.80$ \\
\hline Mexico & 42,907 & 18,755 & 5 & 42,907 & 858.14 & $24,886.06$ & $25,744.20$ \\
\hline Chiapas & 42,907 & 18,755 & 5 & 42,907 & 858.14 & $24,886.06$ & $25,744.20$ \\
\hline Chanal & 3,543 & 1,730 & 1 & 3,543 & $\$ 70.86$ & $2,054.94$ & $2,125.80$ \\
\hline Huixtán & 5,893 & 2,579 & 1 & 5,893 & 117.86 & $3,417.94$ & $3,535.80$ \\
\hline Oxchuc & 12,812 & 5,134 & 1 & 12,812 & 256.24 & $7,430.96$ & $7,687.20$ \\
\hline San Juan Cancuc & 9,091 & 4,284 & 1 & 9,091 & 181.82 & $5,272.78$ & $5,454.60$ \\
\hline Tenejapa & 11,568 & 5,028 & 1 & 11,568 & 231.36 & $6,709.44$ & $6,940.80$ \\
\hline Grand Total & 860,681 & 301,407 & 51 & 927,563 & $18,551.26$ & $537,986.54$ & $556,537.80$ \\
\hline
\end{tabular}


prevalence and population at risk of STH in the LAC region. The fact that this tool allows us to say, for any state, department, municipality or district in the region, that given the prevalence of determinants at the time of the last census, it is possible that the prevalence of STH in that unit is around $x \%$ (a given percentage, the particular predicted prevalence of any given unit), could be valuable for writing proposals, mobilising resources, calculating sample sizes for prevalence studies and setting control targets in the absence of empirical data. Furthermore, these values can be aggregated, not just at national or first administrative level, but to any group of municipalities that is deemed relevant, using the "pivot chart" function in Excel. As an example of this, Table 9 shows the aggregated values generated by the model when it is restricted to only those municipalities or departments that have been targeted by the Inter-American Development Bank (IDB) for NTD projects.

\section{Acknowledgements}

We thank the Regional Neglected Infectious Diseases Program at the Pan American Health Organization for facilitate access to databases of STH epidemiological data resulting of a review of the literature published during the last 10 years in the region of the Americas.

\section{Disclaimer}

The authors Josh Colston (Inter-American Development Bank) and Martha Saboyá (Pan-American Health Organization) declare that the contents of this paper are the sole responsibility of its authors and should not be construed as speaking for the policies of the Pan American Health Organization, the World Health Organization or the Inter-American Development Bank. This paper is a tool towards further scientific dialogue and discussion among public health professionals.

\section{References}

Ahmed A, Al-Mekhlafi HM, Choy SH, Ithoi I, Al-Adhroey AH, Abdulsalam AM, Surin J, 2011. The burden of moderate-toheavy soil-transmitted helminth infections among rural Malaysian Aborigines: an urgent need for an integrated control programme. Parasit Vectors 4, 242.

Al-Mekhlafi MSH, Atiya AS, Lim YAL, Mahdy AKM, Ariffin WAW, Abdullah HC, Surin J, 2007. An unceasing problem: soil-transmitted helminthiases in rural Malaysian communities. Southeast Asian J Trop Med Public Health 38, 998-1007. Asaolu SO, Holland CV, Jegede JO, Fraser NR, Stoddard RC, Cromptod DW, 1992. The prevalence and intensity of soil- transmitted helminthiases in rural communities in Southern Nigeria. Ann Trop Med Parasitol 86, 279-287.

Balen J, Raso G, Li YS, Zhao ZY, Yuan LP, Williams GM, Luo XS, Shi MZ, Yu XL, Utzinger J, Mc Manns DP, 2011. Risk factors for helminth infections in a rural and a peri-urban setting of the Dongting Lake area, People's Republic of China. Int J Parasitol 41, 1165-1173.

Bitrán R, Martorell B, Escobar L, Munoz R, Glassman A, 2009. Controlling and eliminating neglected diseases in Latin America and the Caribbean. Health Affairs 28, 1707-1719.

Brooker S, 2007. Spatial epidemiology of human schistosomiasis in Africa: risk models, transmission dynamics and control. Trans R Soc Trop Med Hyg 101, 1-8.

Brooker S, Beasley M, Ndinaromtan M, Madjiouroum EM, Baboguel, Elie Djenguinabe E, Hay SI, Bundy DAP, 2002. Use of remote sensing and a geographical information system in a national helminth control programme in Chad. Bull World Health Organ 80, 783-789.

Brooker S, Clements ACA, Bundy DAP, 2006. Global epidemiology, ecology and control of soil-transmitted helminth infections. Adv Parasitol 62, 221-261.

Brooker S, Michael E, 2000. The potential of geographical information systems and remote sensing in the epidemiology and control of human helminth infections. Adv Parasitol 47, 245-288.

Brooker S, Singhasivanon P, Waikagul J, Supavej S, Kojima S, Takeuchi T, Luong TV, Looareesuwan S, 2003. Mapping soiltransmitted helminths in Southeast Asia and implications for parasite control. Southeast Asian J Trop Med Public Health 34, 24-36.

Cattaneo MD, Galiani S, Gertler PJ, Martinez S, Titiunik R, 2007. Housing, health, and happiness. SSRN eLibrary (August 1). Available at: http://papers.ssrn.com/sol3/papers.cfm? abstract_id=981822 (accessed on April 2012).

Chammartin F, Scholte RG, Guimarães LH, Tanner M, Utzinger J, Vounatsou P, 2013. Soil-transmitted helminth infection in South America: a systematic review and geostatistical metaanalysis. Lancet Infect Dis 13, 507-518.

Chan MS, Medley GF, Jamison D, Bundy DA, 1994. The evaluation of potential global morbidity attributable to intestinal nematode infections. Parasitology 109, 373-387.

de Silva NR, Brooker S, Hotez PJ, Montresor A, Engels D, Savioli L, 2003. Soil-transmitted helminth infections: updating the global picture. Trends Parasitol 19, 547-551.

Gamboa MI, Basualdo JA, Kozubsky L, Costas E, Cueto Rua E, Lahitte HB, 1998. Prevalence of intestinal parasitosis within three population groups in La Plata, Argentina. Eur J Epidemiol 14, 55-61.

Guyatt H, 2003. The cost of delivering and sustaining a control programme for schistosomiasis and soil-transmitted helminthiasis. Acta Trop 86, 267-274.

Hall A, Horton S, de Silva N, 2009. The costs and cost-effectiveness of mass treatment for intestinal nematode worm infec- 
tions using different treatment thresholds. PLoS Negl Trop Dis 3, e402.

Hotez, PJ, Bundy DAP, Brooker S, Drake L, de Silva N, 2006. Helminth infections: soil-transmitted helminth infections and schistosomiasis. Available at: http://www.ncbi.nlm.nih.gov/books /NBK11748/ (accessed on April 2012).

Hui X, 2011. Effects of health education on integrated control of soil-transmitted nematodes. Chin J Schisto Control 23, 595-597.

Maia MMM, Fausto MA, Vieira ELM, Benetton MLFN, Carneiro M, 2009. Intestinal parasitic infection and associated risk factors, among children presenting at outpatient clinics in Manaus, Amazonas State, Brazil. Ann Trop Med Parasitol 103, 583-591.

Montresor A, Crompton DWT, Hall A, Bundy DAP, Savioli L, 1998. Guidelines for the evaluation of soil-transmitted helminthiasis and schistosomiasis at community level. Geneva: World Health Organization. Available at: http://whqlibdoc. who.int/hq/1998/WHO_CTD_SIP_98.1.pdf (accessed on April 2012).

Montresor A, Gabrielli AF, Diarra A, Engels D, 2010. Estimation of the cost of large-scale school deworming programmes with benzimidazoles. T Roy Soc Trop Med H 104, 129-132.

Morales-Espinoza EM, Sánchez-Pérez HJ, del Mar García-Gil M, Vargas-Morales G, Méndez-Sánchez JD, Pérez-Ramírez M, 2003. Intestinal parasites in children, in highly deprived areas in the border region of Chiapas, Mexico. Salud Pública de México 45, 379-388.

Murray CJ, Lopez AD, 1997. Global mortality, disability, and the contribution of risk factors: global burden of disease study. Lancet 349, 1436-1442.

Pan American Health Organization, 2009. Epidemiological profiles of neglected diseases and other infections related to poverty in Latin America and the Caribbean. Washington DC. Available at: http://new.paho.org/hq/dmdocuments/2009/ndsepi-profiles.pdf (accessed on April 2012).

Quihui L, Valencia ME, Crompton DWT, Phillips S, Hagan P, Morales G, Díaz-Camacho SP, 2006. Role of the employment status and education of mothers in the prevalence of intestinal parasitic infections in Mexican rural schoolchildren. BMC Public Health 6, 225.

Saboyá M, Catalá L, Ault SK, Nicholls RS, 2011. Prevalence and intensity of infection of soil-transmitted helminths in Latin America and the Caribbean countries mapping at second administrative level 2000-2010. Washington DC: Pan American Health Organization.

Smith H, Dekaminsky R, Niwas S, Soto R, Jolly P, 2001. Prevalence and intensity of infections of Ascaris lumbricoides and Trichuris trichiura and associated socio-demographic variables in four rural Honduran communities. Mem Inst Oswaldo Cruz 96, 303-314.

Sturrock HJW, Picon D, Sabasio A, Oguttu D, Robinson E, Lado M, Rumunu J, Brooker S, Kolaczinski JH, 2009. Integrated mapping of neglected tropical diseases: epidemiological findings and control implications for northern Bahr-elGhazal State, Southern Sudan. PLoS Negl Trop Dis 3, e537.

Victora CG, Huttly SR, Fuchs SC, Olinto MT, 1997. The role of conceptual frameworks in epidemiological analysis: a hierarchical approach. Int J Epidemiol 26, 224-227.

WHO, 2006. Preventive chemotherapy in human helminthiasis. Geneva. World Health Organ Available at: http://whqlibdoc.who.int/publications/2006/9241547103_eng.pdf (accessed on April 2012).

WHO, 2007. Preventive chemotherapy in human helminthiasis: an implementation guide for programme managers - Lecturer's manual Geneva. Geneva: World Health Organization.

WHO, 2011. Soil-transmitted helminthiases: estimates of the number of children needing preventive chemotherapy and number treated, 2009. Wekl Epidemiol Rec 86, 257-267.

WHO/UNICEF Joint Monitoring Programme (JMP) for water supply and sanitation. 2010. Country files. Available at: http://www.wssinfo.org/definitions-methods/watsan-categories/ (accessed on April 2012).

WHO UNICEF WHO/UNICEF Joint Monitoring Programme (JMP) for water supply and sanitation, 2003. Types of drinking-water sources and sanitation. Available at: http://www.wssinfo.org/documents-links/documents/?tx_displaycontroller[type]=country_files (accessed on April 2012).

Zhou XN, Lv S, Yang GJ, Kristensen TK, Bergquist NR, Utzinger J, Malone JB, 2009. Spatial epidemiology in zoonotic parasitic diseases: insights gained at the 1st international symposium on geospatial health in Lijiang, People's Republic of China, 2007. Parasit Vectors 2, 10.

Ziegelbauer K, Speich B, Mäusezahl D, Bos R, Keiser J, Utzinger J, 2012. Effect of sanitation on soil-transmitted helminth infection: systematic review and meta-analysis. PLoS Med 9, e1001162. 